\title{
Trends and low-frequency variability of storminess over western Europe, 1878-2007
}

\author{
Xiaolan L. Wang $\cdot$ Hui Wan $\cdot$ Francis W. Zwiers \\ Val R. Swail · Gilbert P. Compo • Robert J. Allan • \\ Russell S. Vose $\cdot$ Sylvie Jourdain $\cdot$ Xungang Yin
}

Received: 3 June 2010/Accepted: 21 May 2011/Published online: 8 July 2011

(C) Her Majesty the Queen in the Right of Canada as represented by the Minister of the Environment 2011

\begin{abstract}
This study analyzes extremes of geostrophic wind speeds derived from sub-daily surface pressure observations at 13 sites in the European region from the Iberian peninsula to Scandinavia for the period from 1878 or later to 2007. It extends previous studies on storminess conditions in the Northeast (NE) Atlantic-European region. It also briefly discusses the relationship between storminess and the North Atlantic Oscillation (NAO). The results show that storminess conditions in the region from the Northeast Atlantic to western Europe have undergone substantial
\end{abstract}

\author{
X. L. Wang $(\bowtie) \cdot$ H. Wan · F. W. Zwiers · V. R. Swail \\ Climate Research Division, Science and Technology Branch, \\ Environment Canada, Toronto, ON, Canada \\ e-mail: Xiaolan.Wang@ec.gc.ca \\ G. P. Compo \\ CIRES, Climate Diagnostics Center, University of Colorado, \\ Boulder, CO, USA \\ G. P. Compo \\ NOAA Earth System Research Laboratory, Physical Sciences \\ Division, Boulder, CO, USA \\ R. J. Allan \\ Hadley Centre, Met Office, Exeter, UK \\ R. S. Vose \\ NOAA's National Climatic Data Center, Asheville, NC, USA \\ S. Jourdain \\ Meteo-France, Direction de la Climatologie, Toulouse, France \\ $X$. Yin \\ STG Inc., Asheville, NC, USA \\ Present Address: \\ F. W. Zwiers \\ Pacific Climate Impacts Consortium, University of Victoria, \\ Victoria, BC, Canada
}

decadal or longer time scale fluctuations, with considerable seasonal and regional differences (especially between winter and summer, and between the British Isles-North Sea area and other parts of the region). In the North Sea and the Alps areas, there has been a notable increase in the occurrence frequency of strong geostrophic winds from the mid to the late twentieth century. The results also show that, in the cold season (December-March), the NAO-storminess relationship is significantly positive in the north-central part of this region, but negative in the south-southeastern part.

\section{Introduction}

Observed warming of the climate system is unequivocal (IPCC 2007). As the climate warms, the subtropical highpressure systems are projected to expand poleward associated with an expansion of the Hadley Circulation and annular mode changes (NAM/NAO and SAM), with increased water vapour in the atmosphere and increased water vapour transport out of the subtropics (Meehl et al. 2007; Solomon et al. 2007). The mid-latitude jet streams are projected to strengthen in the upper troposphere and lower stratosphere and to shift poleward in the troposphere (Ihara and Kushner 2009; Lorenz and DeWeaver 2007; Kushner et al. 2001). The most important changes that are anticipated in the mid-latitude storm climate include: (1) a poleward shift of the mid-latitude storm tracks (Meehl et al. 2007), (2) an increased number of storms for certain regions (e.g., Great Britain, Aleutian Isles) and (3) a minor reduction in the total number of cyclones (e.g., Ulbrich et al. 2009; Loptien et al. 2008; Leckebusch et al. 2006; Lambert and Fyfe 2006). In particular, for the British Isles/ North-Sea/western Europe region, a 20-year storm event could become a 10-year event around 2030-2040, and a 
5-6 year event by 2100 (Della-Marta and Pinto 2009). Such changes in storm climate could have considerable impacts on society and the environment, and thus are of great concern.

There have been reports of observed changes in extratropical cyclone activity over the second half of the twentieth century, which are characterized by a significant decrease in activity in the mid-latitudes and an increase in the high latitudes of the northern hemisphere, suggesting a poleward shift of the storm track in winter (e.g., McCabe et al. 2001; Gulev et al. 2001; Wang et al. 2006a, b; Ulbrich et al. 2009). It would be interesting to know whether these reported trends have continued in the last decade.

There is also an urgent need to provide analysis of alternative datasets produced with a range of metrics to reach a quantitatively robust conclusion about the climate trends and variability of the last century, especially those in the extremes such as atmospheric storminess or cyclone activity. Over the oceans, centennial time series of visual observations of surface wind waves have been analyzed to assess historical trends in ocean wave heights (Gulev and Grigorieva 2004, 2006), which can be used as an alternative metric of storminess, corroborated by the fact that observed changes in ocean wave heights (Wang and Swail 2006; Gulev and Grigorieva 2006) are consistent with observed changes in storminess (Wang et al. 2008). There have also been some attempts to study storminess by analyzing historical weather maps (e.g., Schinke 1993), which have temporal homogeneity problems (von Storch et al. 1993). For the late nineteenth century and the twentieth century, European station data open up an excellent prospect for advances based on purely in-situ data analysis for the highly variable Atlantic-European sector, and also provide a basis for validating centennial gridded products from Numerical Weather Prediction models, such as the Twentieth Century Reanalysis (Compo et al. 2011).

In some studies, long-term historical sub-daily observations of surface pressure have been used to calculate geostrophic wind speeds and their extremes, which were used to infer historical storminess conditions over the northeast Atlantic-European region (see Fig. 2), and to assess historical changes therein (Alexandersson et al. 1998, 2000; Matulla et al. 2008; Wang et al. 2009). Surface pressure observations have been used for this purpose because they are much more reliable and temporally homogeneous than surface wind observations (Schmidt and von Storch 1993), though centennial time series of surface wind speed data have also been used to study storminess climate (e.g., Sweeney 2000). Also, it has been found that extremes of extratropical geostrophic wind speeds derived from sub-daily surface pressure observations well approximate ERA40 surface wind speed extremes (Wang et al. 2009; referred to as W09 hereinafter).
In this study, we aim to extend the region analyzed by W09 and Alexandersson et al. $(1998,2000)$ southward to Iberia and eastward to central Europe, as shown in Fig. 2. We augmented the geostrophic wind dataset of W09 by deriving sub-daily geostrophic wind speeds and their extremes for an additional 14 triangles (Fig. 2) in this region for the period from 1878 or later to 2007, to assess the historical storminess conditions and whether trends have continued into the early twenty-first century. Similar to W09, we also briefly discuss the relationship between the storminess conditions and the North Atlantic Oscillation (NAO).

\section{Data and procedure}

The sub-daily sea level pressure (SLP) data analyzed in this study were obtained from the International Surface Pressure Databank (Yin et al. 2008). The sites (and stations) providing the historical SLP data analyzed here are listed in Table 1 and shown in Fig. 2, along with those analyzed in W09. The data quality control and interpolation procedures are as in W09, which are also briefly described in the Appendix.

In this study 14 new pressure triangles are formed (from sites 1-13 in Table 1) and analyzed to augment the triangles of W09. These are listed in Table 2 and shown in Fig. 2 by larger letters. We also analyze the triangles analyzed in W09, using a better sampling technique to reduce aliasing effects (as detailed later in this section). As noticed in W09, the configuration of the triangles is important; triangles that are too large tend to mask differences among different parts of the triangle area. Extreme geostrophic wind speeds from smaller triangles should correspond better with the areal maximum surface wind speed than those from larger triangles, because a geostrophic wind speed represents an average wind condition over the triangle region. These factors were considered when constructing the triangles; the triangles shown in Fig. 2 are the smallest and most comparable in size that can be constructed from the available sites with long term subdaily pressure observations. They should represent the long term trend in storm activity, although the degree of approximation of geostrophic wind speeds to the corresponding surface wind speeds could be compromised in regions of complex terrain (better approximation is expected over smooth surfaces, such as oceanic areas).

For each triangle, sub-daily instantaneous geostrophic wind speeds are calculated from the sub-daily instantaneous SLP values for the same hour at the three sites that form the triangle when none of the three values are missing (see W09 for details). For each triangle, the times (GMT) for which the geostrophic wind speeds were calculated and used in this study are also listed in Table 2. The 
Table 1 The twenty sites and the related stations of sea level pressure (SLP) data analyzed in this study (sites 1-13) and in Wang et al. (2009) (sites 10-20; note that sites 10-13 are included in both studies. See also Fig. 1). A site usually refers to a combination of the stations listed in the second column

\begin{tabular}{|c|c|c|c|c|}
\hline Site & Name of station(s) & Country & Station IDs & $\begin{array}{l}\text { Period of data used } \\
\text { (YYYY.MM.DD.HH) }\end{array}$ \\
\hline 1. Lis & $\begin{array}{l}\text { Lisboa/Geofisico; Cabo Carvoeiro; } \\
\text { Lisboa/Portela }\end{array}$ & Portugal & $535 ; 085300 ; 085360$ & 1863.12.01.09-2007.12.31.23 \\
\hline 2. Gib & Gibraltar; Moron De La Fronter & Spain & 08495; 084950; 083970 & 1852.02.01.09-2007.12.31.23 \\
\hline 3. Mad & Madrid; Madrid/Barajas RS & Spain & $03195 ; 082210$ & 1890.01.01.06-2007.12.31.23 \\
\hline 4. Lac & La_corunya; Lugo/Rozas & Spain & 01387; 080080 & 1865.12.27.09-2007.12.31.23 \\
\hline 5. Bar & Barcelona & Spain & 081810; 0200E; 0201E & 1850.01.01.08-2007.12.31.23 \\
\hline 6. Mil & Milano & Italy & 160800 & 1878.01.01.08-2007.12.31.23 \\
\hline 7. Kre & Kremsmuenster & Denmark & $11012 ; 110120$ & 1874.01.01.06-2007.12.31.23 \\
\hline 8. Par & $\begin{array}{l}\text { Paris-Orly; Evreux; } \\
\text { Le Bourget; St-Maur }\end{array}$ & France & $\begin{array}{l}071490 ; 070380 \\
071500 ; 94068001\end{array}$ & 1872.12.01.10-2007.12.31.23 \\
\hline 9. Sto & Stockholm & Sweden & $024640 ; 09821$ & 1879.01.01.07-2007.12.31.23 \\
\hline 10. Val & Valentia Observatory; Valentia Obs. & Ireland & $03953 ; 039530$ & 1892.01.01.09-2007.12.31.23 \\
\hline 11. deB & de Bilt & Holland & $06260 ; 062600$ & 1902.01.01.07-2007.12.31.23 \\
\hline 12. Ves & Vestervig; Thyboroen & Denmark & 21100; 060520 & 1874.01.01.08-2007.12.31.23 \\
\hline 13. Bod & Bodoe; Bodo VI & Norway & $01152 ; 011520$ & 1900.01.01.08-2008.01.03.23 \\
\hline 14. Sty & Stykkisholmur & Iceland & $04013 ; 040130$ & 1874.01.01.10-2008.01.03.21 \\
\hline 15. Tor & Torshavn & Faroe Islands & $06011 ; 060110$ & 1874.01.01.09-2008.01.03.06 \\
\hline 16. Ber & Bergen-Fredriksberg; Bergen Flesland & Norway & $01316 ; 013110$ & 1868.01.01.08-2008.01.03.23 \\
\hline 17. Abe & Aberdeen/Dyce Airport; Aberdeen Obs. & Great Britain & $03091 ; 030910$ & $\begin{array}{l}\text { 1871.01.01.07-2008.01.03.23 } \\
\text { (no data for 1948-1956) }\end{array}$ \\
\hline 18. Pre & Prestwick(Civ/Navy) & Great Britain & 031350 & 1944.01.01.00-2002.07.10.18 \\
\hline 19. Jan & Jan Mayen(Nor-Navy); Jan Mayen & Norway & $01001 ; 010010$ & 1922.01.01.02-2008.01.03.23 \\
\hline 20. Nor & Nordby; Esbjerg & Denmark & 25140; 060800 & 1874.01.01.08-2008.01.03.21 \\
\hline
\end{tabular}

homogeneity tests and homogenization procedures of W09 were also applied to the new geostrophic wind speed series.

Aliasing occurs when a time series is subsampled at regular intervals, with the result that high-frequency variation not resolved by the longer subsampling interval is "folded" onto lower frequencies. This increases uncertainty in estimates of the mean, for example, because the variance of the mean is approximately equal to the value of the spectral density at the origin divided by the length of the subsampled time series. Madden and Jones (2001) show that "considerable aliased variance can appear at all, even the lowest, frequencies" when the ratio of the averaging length (AL) to the sampling interval (SI) is smaller than unity (namely $\mathrm{AL} / \mathrm{SI}<1$; for example, $\mathrm{AL} / \mathrm{SI}=0.25$ if a time series of seasonal mean values is sampled annually to produce a time series of, for example, DJF mean values). The fact that we analyze the time variation of annual values of quantiles might raise concerns about aliasing, because $\mathrm{AL} / \mathrm{SI}=0.25$ for seasonal quantiles sampled annually in each of the four seasons of the year separately.

To diminish aliasing effects, we first calculate the 95th and 99th percentiles (P95, P99) of all sub-daily geostrophic winds in moving 91-day windows, obtaining a daily series of moving seasonal quantiles. The sampling rate of the resulting daily series of moving seasonal quantiles is $k=365$ times per year. We consider these time series to be unaliased; they have $\mathrm{AL} / \mathrm{SI}=1$. We further calculate the 91-day and 183-day moving averages from the daily P95 and P99 series. Consequently we have three daily time series of each seasonal quantile, the unaveraged series and the two that have been filtered using 91-day and 183-day moving averages respectively. We sample each of the three daily series seasonally, at the four mid-season days (January 15, April 16, July 16, and October 16) of each year, obtaining three seasonal series, whose sampling rate is $k=4$ times per year.

A daily value of a seasonal quantile is set to missing if more than one third of the sub-daily geostrophic winds within the 91-day window centered at this day are missing. An $m$-day moving average value is set to missing if the seasonal quantile for the central day of the $m$-day window is missing, or if more than half of the daily values of the seasonal quantile within the $m$-day window are missing.

Here, an $m$-day moving average of the seasonal quantile involves all sub-daily geostrophic winds within the 
Table 2 Pressure triangles formed and analyzed in this study, as well as the Kendall's slope estimates $\hat{\beta}$ and its significance level $\alpha((1-\alpha)$ is shown in parentheses) for the corresponding seasonal P95 and P99 storm index series for the period analyzed (see Sect. 2)

\begin{tabular}{|c|c|c|c|c|c|c|}
\hline Triangle (Abbreviation) & Year1 & GMT hours & $\begin{array}{l}\text { Winter } \\
\hat{\beta}(1-\alpha)\end{array}$ & $\begin{array}{l}\text { Spring } \\
\hat{\beta}(1-\alpha)\end{array}$ & $\begin{array}{l}\text { Summer } \\
\hat{\beta}(1-\alpha)\end{array}$ & $\begin{array}{l}\text { Autumn } \\
\hat{\beta}(1-\alpha)\end{array}$ \\
\hline \multicolumn{7}{|c|}{ a. Seasonal P95 storm index } \\
\hline Mad-Gib-Lis (MGL) & 1890 & $9,12,15,18,21$ & $-0.0004(0.567)$ & $-0.00298(0.808)$ & $\mathbf{0 . 0 1 0 1}(0.996)$ & $0.00495(0.940)$ \\
\hline Mad-Gib-Bar (MGB) & 1890 & $6,9,12,15,18$ & $0.00223(0.669)$ & $-0.0014(0.781)$ & $\mathbf{0 . 0 1 1 3}(0.993)$ & $-0.00008(0.507)$ \\
\hline Lac-Lis-Mad (LLM) & 1890 & $9,12,15,18$ & $\mathbf{- 0 . 0 0 7 5}(0.952)$ & $\mathbf{- 0 . 0 1 8 9}(1.000)$ & $-0.0045(0.718)$ & $\mathbf{- 0 . 0 0 8 2 4}(0.997)$ \\
\hline Lac-Val-Lis (LVL) & 1894 & $9,12,15,18$ & $-0.0071(0.937)$ & $-\mathbf{0 . 0 1 9 8}(1.000)$ & $\mathbf{- 0 . 0 2 3 7}(0.999)$ & $\mathbf{- 0 . 0 1 2 7}(0.999)$ \\
\hline Lac-Val-Par (LVP) & 1894 & $9,12,15,18$ & $-0.0051(0.853)$ & $\mathbf{- 0 . 0 0 7 4 9}(0.991)$ & -0.0085 $(0.983)$ & $-0.00269(0.748)$ \\
\hline Mad-Par-Lac (MPL) & 1890 & $9,12,15,18$ & $0.0004(0.544)$ & $-\mathbf{0 . 0 0 7 8 2}(0.998)$ & $\mathbf{0 . 0 1 5 3}(0.978)$ & $0.00249(0.801)$ \\
\hline Mad-Par-Bar (MPB) & 1890 & $6,9,12,15,18$ & $0.00571(0.931)$ & $\mathbf{0 . 0 0 5 6 5}(0.978)$ & $\mathbf{0 . 0 1 5 9}(0.996)$ & $\mathbf{0 . 0 0 8}(0.996)$ \\
\hline Par-Bar-Mil (PBM) & 1878 & $6,9,12,15$ & $\mathbf{0 . 0 0 4 7}(0.960)$ & $0.0074(0.992)$ & $\mathbf{0 . 0 1 3 5}(1.000)$ & $\mathbf{0 . 0 0 7 9 6}(0.996)$ \\
\hline Mil-Par-Kre (MPK) & 1878 & $6,9,12,15,18,21$ & $\mathbf{0 . 0 0 9 0 4}(0.999)$ & $\mathbf{0 . 0 0 9 6 7}(0.981)$ & -0.0111 (0.999) & $0.0075(0.983)$ \\
\hline Val-deB-Par (VDP) & 1892 & $0,3,6,9,12,15,18,21$ & $-\mathbf{0 . 0 0 9 0 9}(0.993)$ & -0.00911 (0.997) & -0.011 (0.994) & $\mathbf{- 0 . 0 0 7 1}(0.996)$ \\
\hline deB-Kre-Par (DKP) & 1892 & $3,6,9,12,15,18,21$ & $-0.0036(0.881)$ & -0.0131 (0.999) & -0.0185 (0.999) & -0.0091 (0.995) \\
\hline Ves-Kre-deB (VKD) & 1892 & $6,9.12,15,18.21$ & $-0.00067(0.560)$ & $-0.00535(0.916)$ & $-0.00443(0.916)$ & $-0.00059(0.573)$ \\
\hline Kre-Ves-Sto (KVS) & 1879 & $6,9,12,15,18,21$ & $-0.00432(0.940)$ & $-0.00698(0.994)$ & $\mathbf{- 0 . 0 1 3 5 5}(0.999)$ & -0.0071 (0.996) \\
\hline Ves-Bod-Sto (VBS) & 1900 & $6,9,12,15,18,21$ & $-0.00518(0.930)$ & $\mathbf{- 0 . 0 0 3 7 8}(0.809)$ & $-0.00879(0.966)$ & $0.00221(0.813)$ \\
\hline APTB & 1875 & $0,3,6,9,12,15,18,21$ & $-0.00082(0.662)$ & $0.00154(0.718)$ & $-0.00128(0.677)$ & $-0.001(0.669)$ \\
\hline APVD & 1904 & $0,3,6,9,12,15,18,21$ & $-0.00028(0.524)$ & $-0.00483(0.895)$ & $-0.00405(0.922)$ & $0.00295(0.819)$ \\
\hline BAPV & 1875 & $0,3,6,9,12,15,18,21$ & $-0.00226(0.832)$ & $-0.0025(0.840)$ & $\mathbf{- 0 . 0 0 8 4 1}(0.992)$ & $-0.00443(0.941)$ \\
\hline BBV & 1901 & $0,3,6,9,12,15,18,21$ & $-0.00044(0.526)$ & $-\mathbf{0 . 0 0 6 3 3}(0.962)$ & $-0.00365(0.880)$ & $0.00362(0.821)$ \\
\hline ВТВ & 1901 & $0,3,6,9,12,15,18,21$ & $-0.00251(0.744)$ & $0.00205(0.674)$ & $-0.00266(0.764)$ & $0.00272(0.789)$ \\
\hline DAPV & 1904 & $0,3,6,9,12,15,18,21$ & $-0.00481(0.907)$ & $-0.00756(0.940)$ & $-\mathbf{0 . 0 1 1 0}(0.998)$ & $-0.00321(0.836)$ \\
\hline JST & 1923 & $0,3,6,9,12,15,18,21$ & $-0.0058(0.878)$ & $0.00682(0.902)$ & $-0.00072(0.567)$ & $-0.00326(0.783)$ \\
\hline JTB & 1923 & $0,3,6,9,12,15,18,21$ & $0.00394(0.799)$ & $\mathbf{0 . 0 0 8 7 5}(0.951)$ & $-0.00405(0.756)$ & $0.00162(0.643)$ \\
\hline VST & 1900 & $0,3,6,9,12,15,18,21$ & $-0.0054(0.941)$ & $-0.00243(0.739)$ & $0.00114(0.644)$ & $-0.00007(0.510)$ \\
\hline VTAP & 1893 & $0,3,6,9,12,15,18,21$ & $0.0021(0.699)$ & $0.00247(0.754)$ & $0.00329(0.892)$ & $0.00305(0.880)$ \\
\hline Field significant at $5 \% 1$ & & & Yes & Yes & Yes & Yes \\
\hline \multicolumn{7}{|c|}{ b. Seasonal P99 storm index } \\
\hline Mad-Gib-Lis (MGL) & 1890 & $9,12,15,18,21$ & $-0.00114(0.661)$ & $-0.00123(0.683)$ & $\mathbf{0 . 0 0 6 0 2}(0.966)$ & $0.00512(0.939)$ \\
\hline Mad-Gib-Bar (MGB) & 1890 & $6,9,12,15,18$ & $-0.0046(0.898)$ & $-0.00313(0.856)$ & $0.00807(0.967)$ & $\mathbf{- 0 . 0 0 5 9 2}(0.977)$ \\
\hline Lac-Lis-Mad (LLM) & 1890 & $9,12,15,18$ & $-\mathbf{0 . 0 0 6 8 4}(0.965)$ & -0.01551 (0.999) & $-0.0104(0.948)$ & $\mathbf{- 0 . 0 1 1 1 5}(0.999)$ \\
\hline Lac-Val-Lis (LVL) & 1894 & $9,12,15,18$ & $-0.00598(0.944)$ & $-\mathbf{0 . 0 2 0 2}(1.000)$ & -0.0206 (0.999) & $\mathbf{- 0 . 0 1 4 9}(0.999)$ \\
\hline Lac-Val-Par (LVP) & 1894 & $9,12,15,18$ & $-0.00724(0.932)$ & $\mathbf{- 0 . 0 0 8 1 7}(0.981)$ & $-0.00700(0.946)$ & $-0.00593(0.921)$ \\
\hline Mad-Par-Lac (MPL) & 1890 & $9,12,15,18$ & $-0.00039(0.557)$ & $-0.00496(0.931)$ & $\mathbf{0 . 0 0 9 5 4}(0.955)$ & $-0.00134(0.687)$ \\
\hline Mad-Par-Bar (MPB) & 1890 & $6,9,12,15,18$ & $0.00365(0.891)$ & $0.00385(0.892)$ & $0.00672(0.933)$ & $0.00256(0.782)$ \\
\hline Par-Bar-Mil (PBM) & 1878 & $6,9,12,15$ & $0.00340(0.914)$ & $\mathbf{0 . 0 0 5 3 3}(0.969)$ & $\mathbf{0 . 0 0 8 7 8}(0.999)$ & $0.00448(0.977)$ \\
\hline Mil-Par-Kre (MPK) & 1878 & $6,9,12,15,18,21$ & $\mathbf{0 . 0 0 6 2 7}(0.990)$ & $0.00595(0.969)$ & $-0.00481(0.870)$ & $0.00447(0.906)$ \\
\hline Val-deB-Par (VDP) & 1892 & $0,3,6,9,12,15,18,21$ & $-\mathbf{0 . 0 0 7 6 4}(0.998)$ & $-0.00815(0.983)$ & $-0.0061(0.942)$ & $\mathbf{- 0 . 0 0 6 1 4}(0.996)$ \\
\hline deB-Kre-Par (DKP) & 1892 & $3,6,9,12,15,18,21$ & $-0.00364(0.889)$ & $-0.00959(0.996)$ & $-0.01667(0.999)$ & $\mathbf{- 0 . 0 0 8 4 4}(0.997)$ \\
\hline Ves-Kre-deB (VKD) & 1892 & $6,9.12,15,18.21$ & $-0.00046(0.560)$ & $-0.00334(0.816)$ & $-0.00313(0.786)$ & $-0.00096(0.601)$ \\
\hline Kre-Ves-Sto (KVS) & 1879 & $6,9,12,15,18,21$ & $-0.00392(0.928)$ & $-0.00666(0.991)$ & $\mathbf{- 0 . 0 1 0 2}(0.999)$ & $\mathbf{- 0 . 0 0 6 5 5}(0.996)$ \\
\hline Ves-Bod-Sto (VBS) & 1900 & $6,9,12,15,18,21$ & $-0.00466(0.882)$ & $-0.00381(0.849)$ & $-0.00107(0.633)$ & $-0.00386(0.849)$ \\
\hline АРТВ & 1875 & $0,3,6,9,12,15,18,21$ & $-0.00034(0.566)$ & $-0.00081(0.587)$ & $-0.00118(0.659)$ & $-0.00247(0.836)$ \\
\hline APVD & 1904 & $0,3,6,9,12,15,18,21$ & $-0.00137(0.665)$ & $-0.00233(0.729)$ & $-0.00242(0.781)$ & $-0.00227(0.743)$ \\
\hline BAPV & 1875 & $0,3,6,9,12,15,18,21$ & $-0.00244(0.816)$ & $-0.00274(0.801)$ & $-\mathbf{0 . 0 0 8 3 4}(0.999)$ & $-\mathbf{0 . 0 0 6 2 2}(0.995)$ \\
\hline BBV & 1901 & $0,3,6,9,12,15,18,21$ & $-0.00164(0.683)$ & $-0.00519(0.946)$ & $-0.00456(0.934)$ & $0.00049(0.551)$ \\
\hline ВТВ & 1901 & $0,3,6,9,12,15,18,21$ & $-0.00237(0.761)$ & $0.00445(0.843)$ & $-0.00164(0.732)$ & $0.00432(0.903)$ \\
\hline DAPV & 1904 & $0,3,6,9,12,15,18,21$ & $-0.00228(0.752)$ & $-0.00728(0.946)$ & $-\mathbf{0 . 0 0 6 9 8}(0.992)$ & $-0.00353(0.886)$ \\
\hline JST & 1923 & $0,3,6,9,12,15,18,21$ & $-0.00478(0.769)$ & $0.00569(0.858)$ & $-0.00258(0.647)$ & $0.00261(0.697)$ \\
\hline JTB & 1923 & $0,3,6,9,12,15,18,21$ & $0.00283(0.729)$ & $\mathbf{0 . 0 1 1 7}(0.994)$ & $-0.00247(0.741)$ & $0.00462(0.861)$ \\
\hline VST & 1900 & $0,3,6,9,12,15,18,21$ & $-0.00228(0.771)$ & $-0.00214(0.709)$ & $0.00008(0.597)$ & $0.00224(0.758)$ \\
\hline VTAP & 1893 & $0,3,6,9,12,15,18,21$ & $0.00164(0.692)$ & $-0.00153(0.690)$ & $0.00113(0.673)$ & $-0.00126(0.672)$ \\
\hline Field significant at $5 \%$ le & & & Yes & Yes & Yes & Yes \\
\hline
\end{tabular}

The GMT hours listed here are those for which geostrophic wind speeds were calculated and analyzed in this study, because they have nearly complete SLP records throughout the period of analysis for all the three sites that form the pressure triangle. The hours not listed here have incomplete records throughout the period (mostly missing in the early decades) and were excluded in this study to ensure data sampling homogeneity. Trends of at least 5 and $20 \%$ significance are shown in bold and italic, respectively 
$(m+90)$-day period centered at the respective mid-season day, although the data in the first and last 45 days of this $(m+90)$-day period are used less often (fewer times) than the other days within the period. For example, a 91-day moving average for a mid-winter day involves all sub-daily geostrophic winds within the 181-day period from 90 days before to 90 days after that mid-winter day, involving half of each shoulder season as well as the central season. Similarly, a 183-day moving average involves data within the 273-day period from 136 days before to 136 days after that mid-winter day, involving both shoulder seasons completely as well as the central season. In other words, a 91-day (183-day) moving average involves data from two (three) seasons centered at the mid-season day.

We use the geostrophic winds calculated for triangle PBM to illustrate the effects of aliasing and the extent to which it can be avoided through filtering and subsequent subsampling. The spectra of the moving seasonal P95 values of the sub-daily geostrophic winds at PBM are shown in Fig. 1 for several different sampling and filtering combinations. The estimated power spectra are divided by the sampling rate $k$, so that each power spectrum integrates to the variance of the time series from which it was calculated when the integral is taken over frequency expressed in cycles per observing interval. Low-pass filtering the unsmoothed daily P95 series by means of a moving average filter should, and does, produce another series that has the same variance at zero frequency. Hence differences in the scaled power spectra at low frequencies after subsampling would reflect aliasing effects and, to some extent, sampling uncertainty, although the latter is expected to be small given the length of our geostrophic wind series.

Note that the red curve in Fig. 1a corresponds to the unfiltered moving seasonal P95 series sampled seasonally in the four seasons consecutively, which are basically the same as the traditional series of consisting of one P95 value for each season separately, except that all the four seasons are now of the same length (91 days) rather than varying between 90 and 92 days. Comparison of the black and red curves in Fig. 1a suggests that a small amount of aliased variance appears in the unaveraged seasonal series (which can be considered to have AL/SI $=1 / 91 \approx 0.01$ ), especially at the decadal and intra-annual scales (near 0.2 and $>0.5$ cycles per year). As shown by the black and green curves in Fig. 1a, the unaveraged daily series and the 90-day moving averaged seasonally sampled series have similar spectra; note that both series have $\mathrm{AL} / \mathrm{SI}=1$. Similarly, AL/SI $\approx 2$ for the 183-day moving averaged seasonally sampled series. As would be expected, the variance at intra-annual scales is reduced when the length of the moving average is taken over 183 rather than 91 days (Fig. 1a, blue curve). In Fig. 1a, the green curve is closest to the black curve, indicating that the 91-day moving averaged seasonally sampled series contains little aliasing effect, and thus we base the remainder of the analysis in this study on seasonally sub-sampled values of 91-day moving averages of daily time series of 91-day moving window quantile estimates.

We also need to sample the 91-day moving averaged series of moving seasonal quantiles annually in each of the four seasons of the year separately, reducing the sampling rate from 4 times per year to one time per year. For such annual series, $\mathrm{AL} / \mathrm{SI}=91 / 365 \approx 0.25$. The spectra of these annual series are shown in Fig. 1b, in comparison with that of the unaveraged daily series and of the 91-day moving averaged seasonally sampled series. Note that the differences between the black and blue or red or dashed curves cannot be completely ascribed to aliasing effects; they also reflect seasonality of long-term trends and of the lagged covariance structure. Nevertheless, the aliasing effect is judged not to be unacceptably large in these annual series. We have to accept these generally small aliasing effects, in order to explore seasonality of long-term trends and variability. Therefore, in this study we use the 91-day moving averaged values of moving seasonal quantiles (95th and 99th percentiles) sampled annually, in each of the four seasons of the year separately. Similar conclusions are obtained when considering geostrophic wind speeds from other triangles.

Since the unaveraged seasonal quantiles sampled annually are analyzed in W09 and Alexandersson et al. (1998, 2000), which are more or less affected by aliasing, we also re-sample seasonal quantiles from the 91-day moving averages of corresponding seasonal quantiles for the 10 triangles analyzed in W09 and repeat the analysis of long-term trends and variations for these triangles. As shown later in Sect. 3, our results for these triangles are basically the same as reported in W09, showing only very small changes in the estimates of trends, which do not change the conclusions. These small changes in results that we obtained in this paper are due to both the elimination of aliasing effect and the different definition of seasons in this study. Each of the four seasons is an extended season in this study (because each of the seasonal quantiles involves all data in a 181-day period, although the data in the 45 days on either side of the central season are used less often than the data within the season); while each season consists of 3 calendar months in W09.

Although the longest period of pressure record extends from January 1852 to January 2008, the majority of sites have no data before 1890 , and a few have no data before 1902 (see Table 1). The longest record of sub-daily geostrophic wind speeds extends from 1878 to January 2008 (Table 2) and all 14 triangles have nearly complete subdaily geostrophic wind speeds for the period of 1902-2007, which is thus referred to as the common period. Among the 

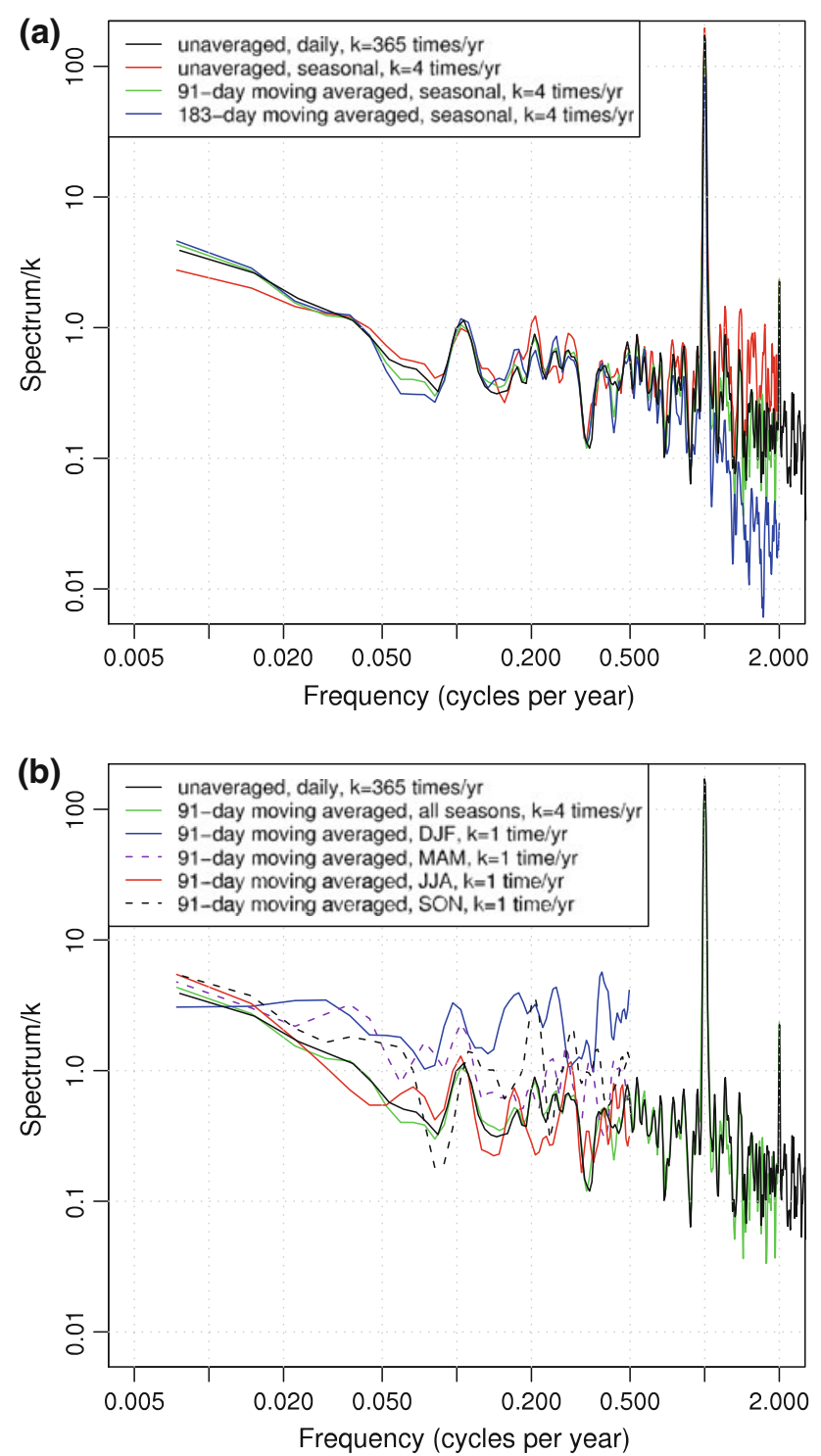

Fig. 1 a The spectrum of the daily series of the moving seasonal P95 of geostrophic winds, and its 91-day and 183-day moving averaged and unaveraged series sampled seasonally. b The spectrum of the unaveraged daily series of the moving seasonal P95, and of the 91-day moving averaged series sampled seasonally in all 4 seasons, and sampled annually in DJF, MAM, JJA, and SON, separately

10 pressure triangles analyzed in W09, all but triangles JST and JTB (the two most northerly triangles) also have nearly complete sub-daily geostrophic wind speeds for this common period. Therefore, triangles JST and JTB are excluded from the contour mapping of trends shown later in Sect. 3.

In order to diminish the differences due to differences in the triangle size and in the period of data record, the annual series of each seasonal quantile is normalized, with respect to the mean and standard deviation of the 100-year period from 1908 to 2007. The same 11-point Gaussian smoother and the same Kendall trend analysis as in W09 were applied to the resulting P95 and P99 storm index series.

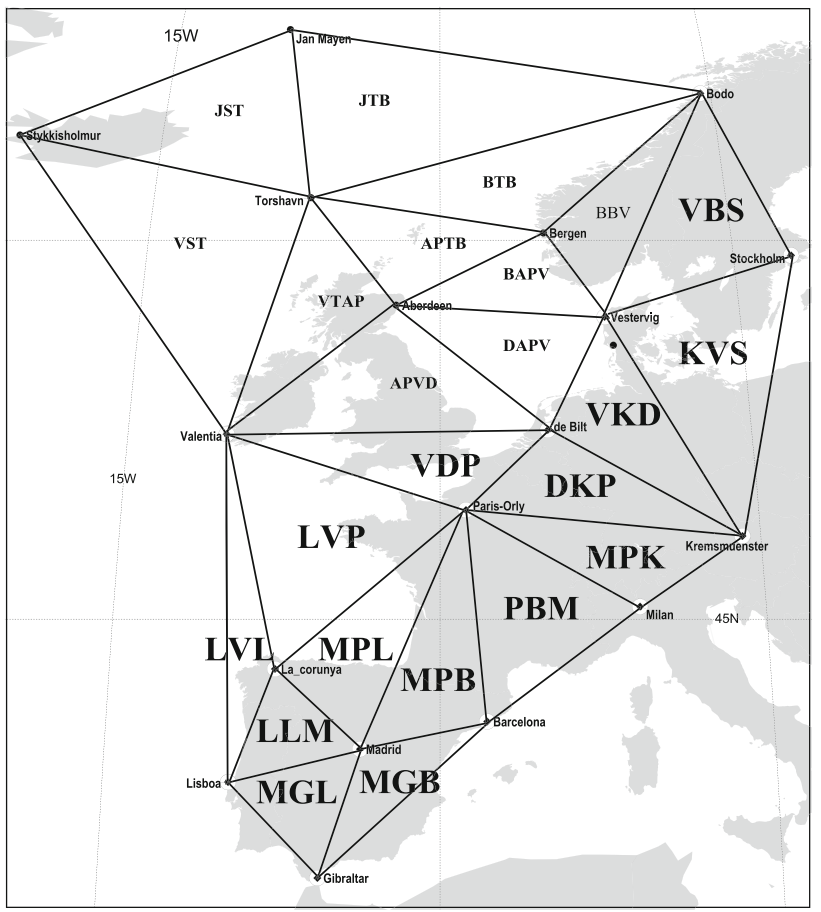

Fig. 2 The sites indicated with open circles and the triangles marked with larger letters are analyzed in this study. The other triangles (and sites) were included in the studies of Alexandersson et al. (1998, 2000) and Wang et al. (2009)

Note that the Gaussian smoothed lines better represent the long-term variability and trends than do the linear trend estimates, although both are shown and discussed in the next section. The Kendall's trend estimates for the period analyzed and assessments of whether they are significantly different from zero are also summarized in Table 2, shown in Fig. 3, and discussed below.

Note that the trend significance test is performed for the extreme geostrophic wind speed series over each triangle region. In other words, multiple (local) tests for significance of trend in storminess are conducted for the region analyzed. In this case, the joint statistical significance of the multiple tests (i.e., field significance) should be evaluated. We use the Walker's test to do so in this study, because it is shown in Wilks (2006) to be more powerful than the traditional method of Livezey and Chen (1983). In particular, it is relatively insensitive to non-independence of the local test results (Wilks 2006). The resulting field significance estimates are given in Table 2 and discussed below.

\section{Long-term trends and low-frequency variability of storminess}

Figure 3 shows the Gaussian smoothed lines and the estimated linear trends in winter and summer seasonal P99 
a Winter (DJF)

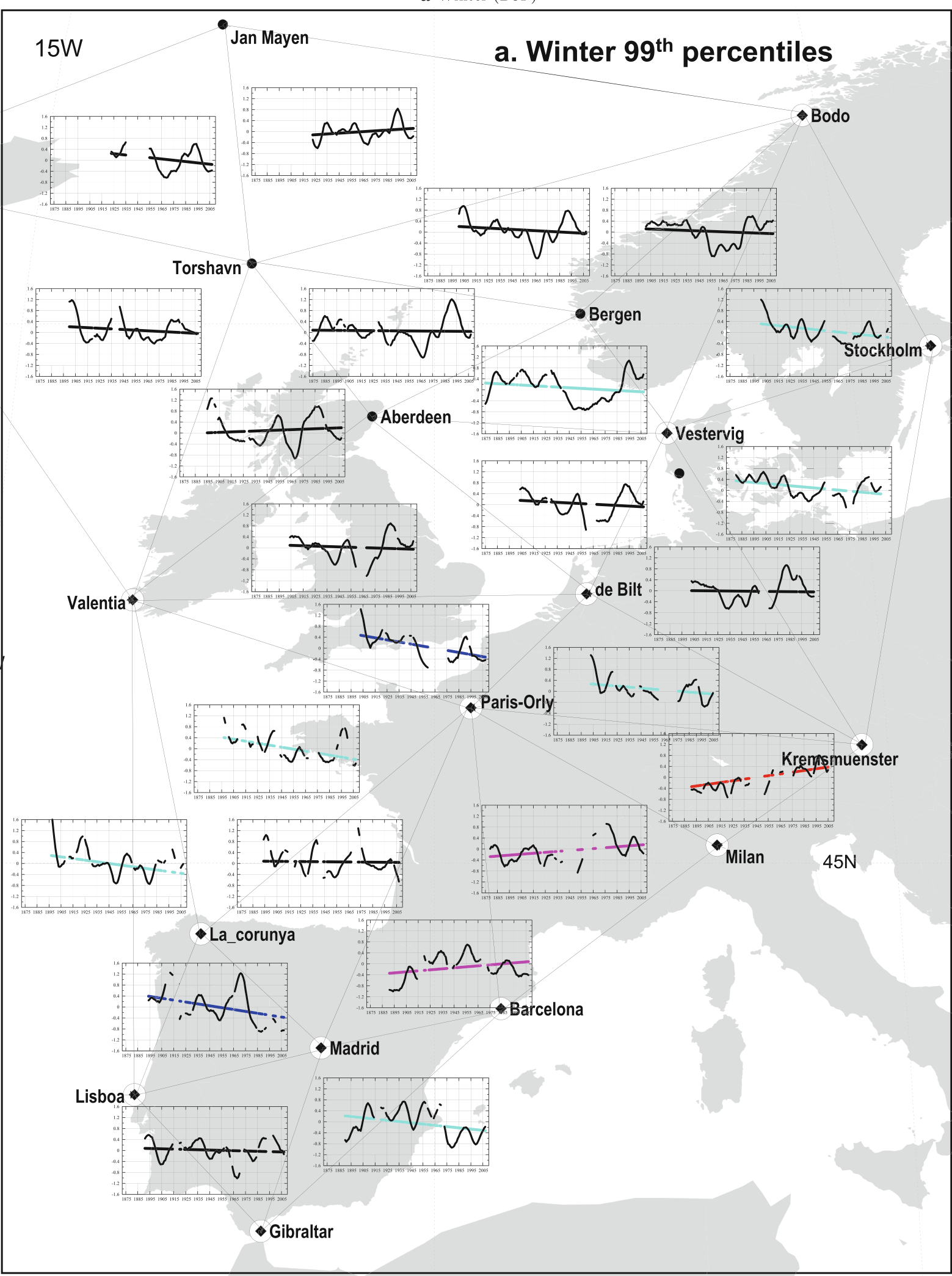

Fig. 3 The Gaussian low-pass filtered curves and the estimated linear trends of the indicated seasonal P99 storm index series for the pressure triangles shown. The ticks of the time (horizontal) axis range from 1875 to 2005 , with an interval of 10 years. The disconnections in the lines show periods of missing data. Red and magenta (blue and cyan) trend lines indicate upward (downward) trends of at least 5 and $20 \%$ significance, respectively 
b Summer (JJA)

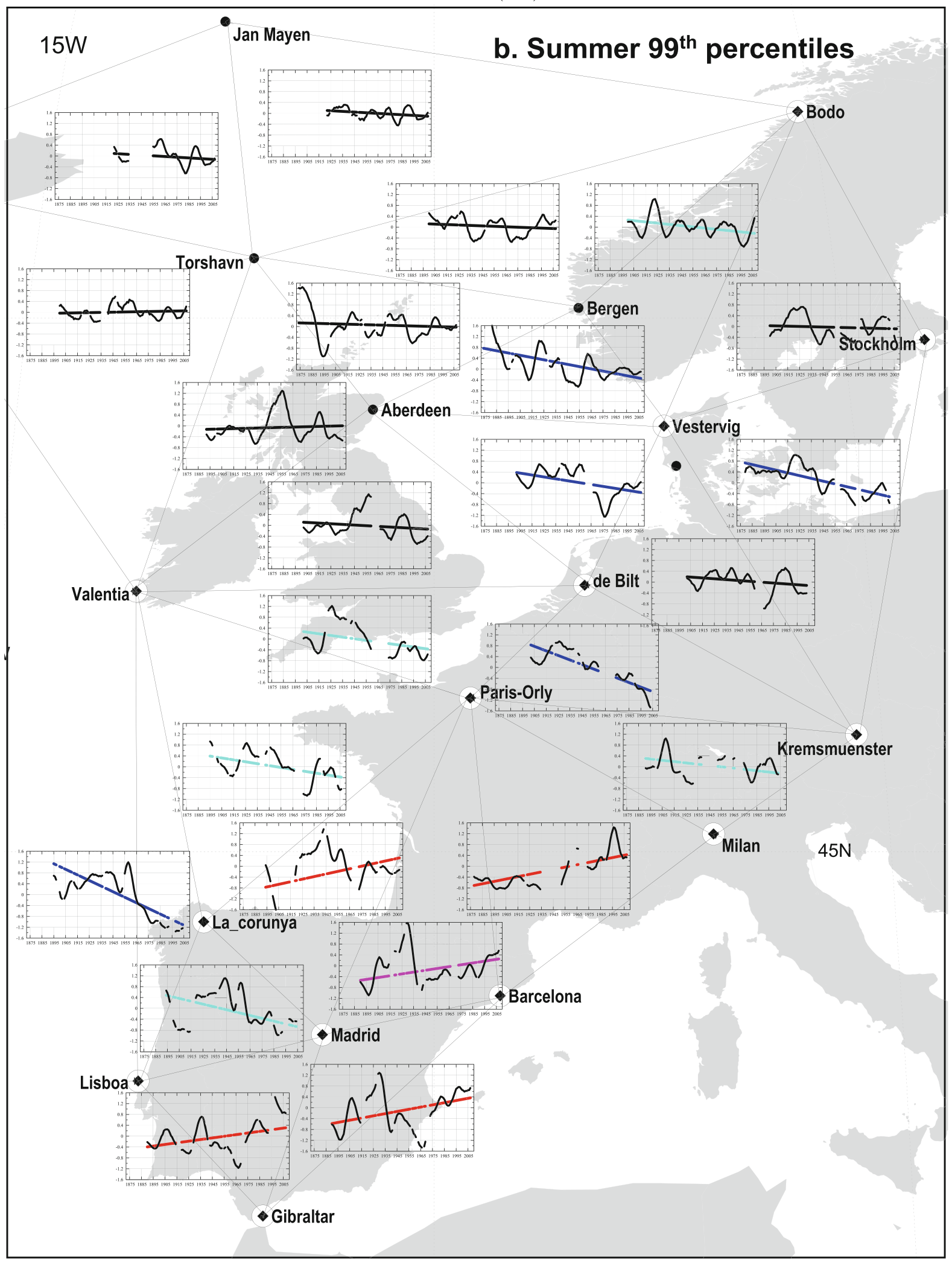

Fig. 3 continued 
storm index series for each of the 24 triangles analyzed in this study. Figure 4 show contour maps of 20 -year mean values of the seasonal P99 storm index for each of the four seasons, separately, for each of six 20-year periods (amongst which the first two overlap slightly). The Kendall's linear trend estimates for the common period are obtained and shown in Fig. 5.
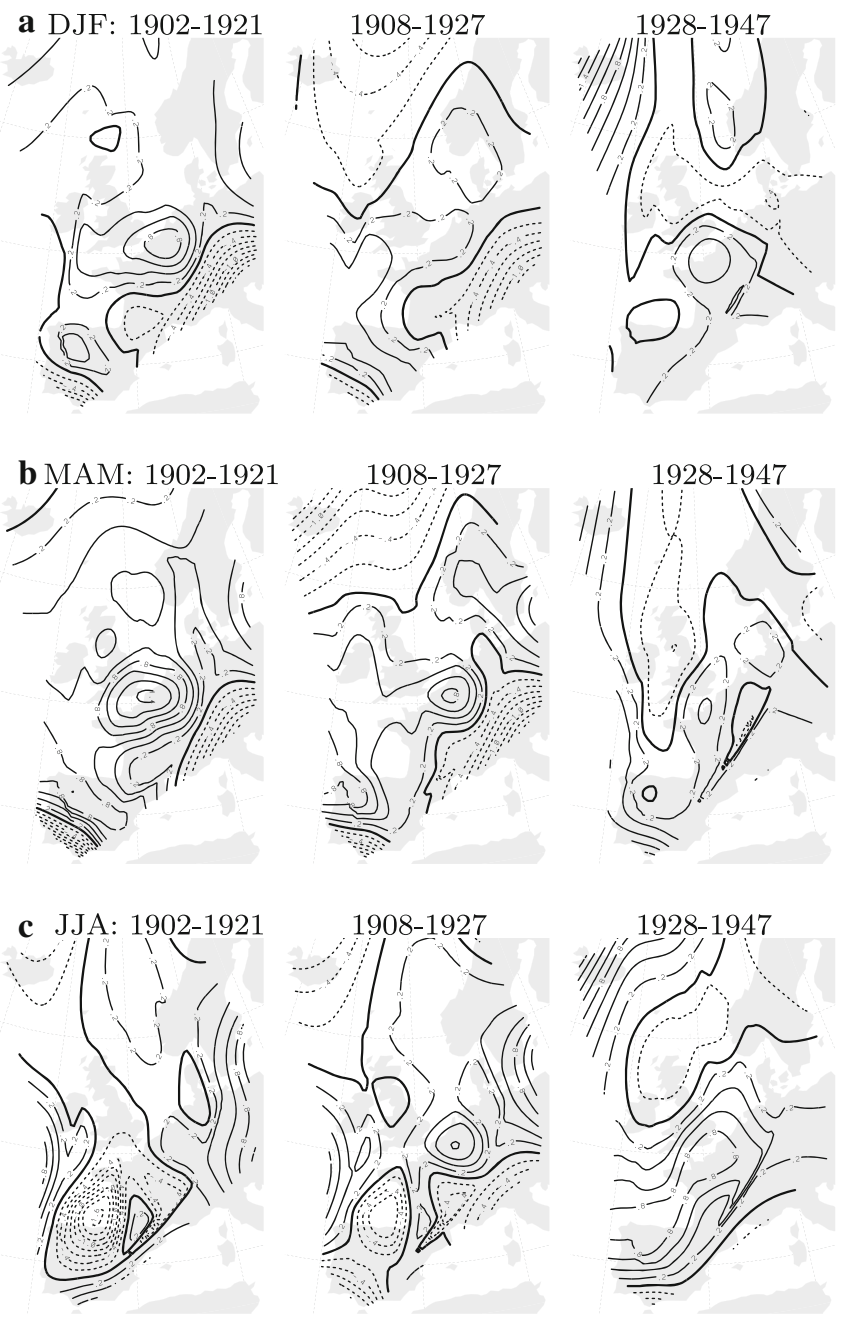

d SON: 1902-1921
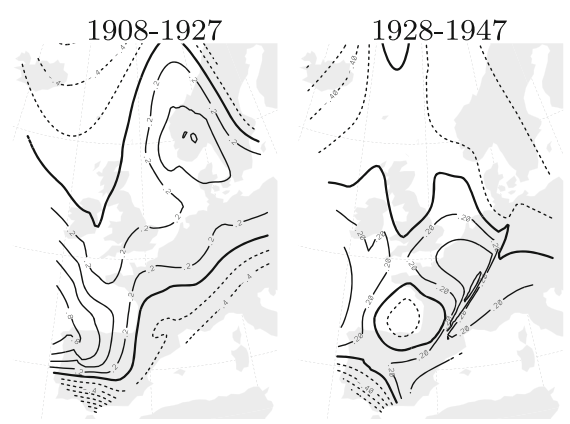

Fig. 4 Contour maps of 20-year means of the indicated seasonal P99 storm index for the indicated 20-year periods (note that only the first two 20-year periods overlap). Row a shows results for December through February (DJF), b March through May (MAM), c June
Similar to what was noted in W09, decadal or longer time scale variability in storminess is very profound in this region. The previously reported trends seen in the second half of the twentieth century (McCabe et al. 2001; Gulev et al. 2001; Wang et al. 2006a, b) seem to have continued into the early twenty-first century. For the North Sea area in winter, as shown in Fig. 3a, the 1960s-1970s is the
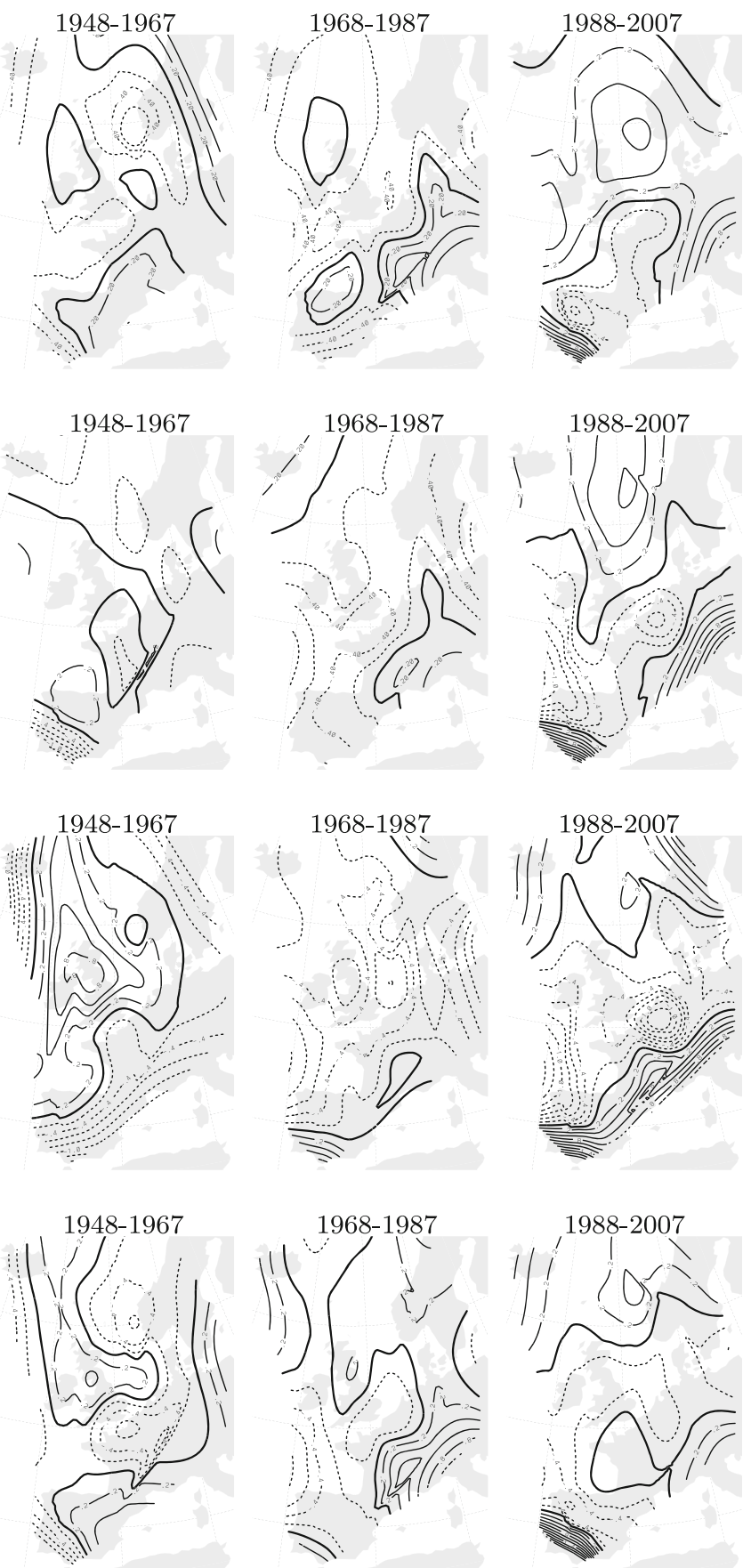

through August (JJA), and d September through November (SON). The contour interval is 0.2 . The bold lines represent zero contours. The dashed and thin solid lines represent negative and positive values, respectively 

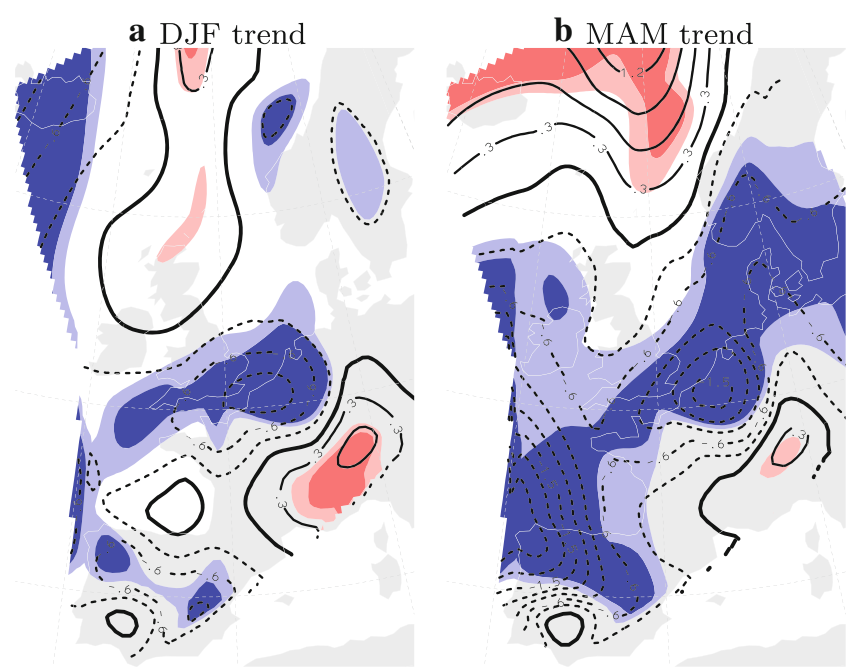

Fig. 5 Contour maps of Kendall's linear trend estimates (in unit per century) for the common period 1902-2007 in the indicated seasons. The contour interval is 0.3 . The zero contours are shown in bold. Positive trends are shown in thin solid contours, and reddish shadings

calmest period, while the 1990s is the roughest period in the record. There are also large seasonal and regional differences in trends and variability, as shown in Figs. 3, 4 and 5. The most striking seasonal differences are seen between winter (DJF) and summer (JJA), which is not surprising given the different circulation regimes dominating in different seasons (more details later in this section). In terms of Kendall's linear trend estimates, the most significant winter storminess trend in western Europe is seen in the Alps region. Namely, winter storminess shows a steady increasing trend in the region from Paris to Kremsmuenster to Barcelona to Madrid (see triangles MPK, PBM, and MPB in Fig. 3a; see also Fig. 5a). It is also shown that winter storminess appears to have slightly declined over northern Europe (east of Denmark; including triangles KVS and VBS) and southeastern Iberia (triangles MGB and LLM; see Figs. 3a and 5a), while there is an unprecedented maximum in the early 1990s in the North Sea-British Isles area (see W09 for more details). The latter is also very clearly shown in the series of 20 -yr mean storminess conditions [see the first row of Fig. 4; the positive anomalies of $0.4-0.8$ seen over the North Sea in the last 20-year period (1988-2007) are unprecedented in any of the previous five 20 -year periods]. Note that the geostrophic wind speeds and the ERA40 surface wind speeds have been shown to have very similar trends and low-frequency variations in the extremes (99th percentiles; see W09, Fig. 5).

As shown in Fig. 6a, in the North Sea area, there has been a notable increase in the occurrence frequency of moderate-strong geostrophic winds from the mid to the late twentieth century, while the increase in the earlier half of the century is mostly in the occurrence frequency of
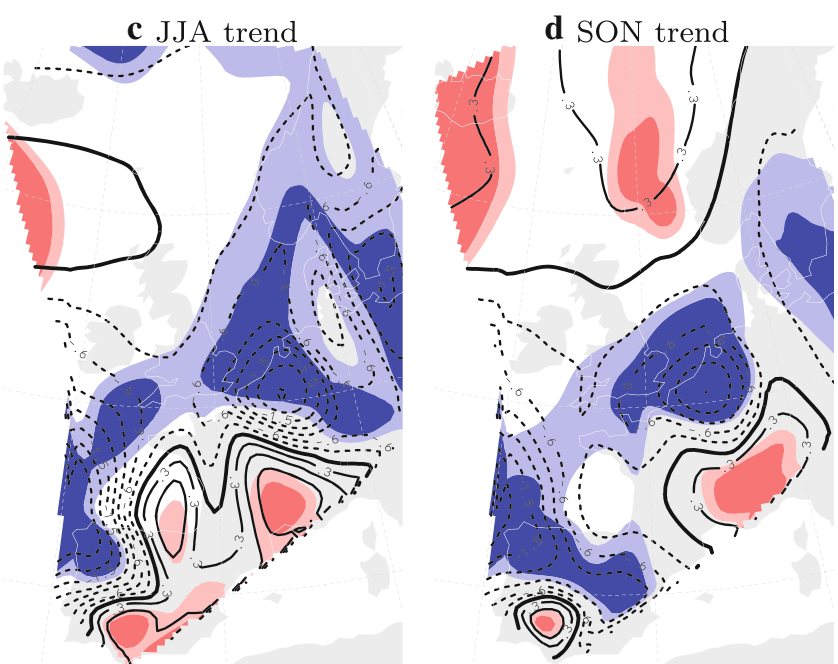

when they are of at least $20 \%$ significance; and negative trends in dashed contours and bluish shadings. The darker shadings indicate areas of trends of at least $5 \%$ significance

weaker geostrophic winds. The peak in the early 1990s is unprecedented only in the high (99th) percentiles; it is not the highest peak in the 50th and 25th percentiles (Fig. 6, left panels). In terms of linear trend, only the 50th percentiles show a marginally significant downward trend, with no significant trend in the other quantiles, as shown in the left panels of Fig. 6. In the Alps (Fig. 6, right panels), however, an increase has been observed in all percentiles shown; the distribution has a heavier tail than that of the APTB triangle. Note that there has been a notable increase in the upper tail $\left(\geq 20 \mathrm{~m} \mathrm{~s}^{-1}\right)$ in the recent decades in both triangle regions (Fig. 6a, b).

In contrast, summer storminess trends are characterized by a decreasing trend in the region from the Bay of Biscay to the North Sea to central Europe, with a significant increasing trend over southern and eastern Iberia and the French Alps, and no significant change in the other parts of the region analyzed (Figs. 3b, 5c). Spring storminess appears to have an increasing trend in the Alps region, but a decreasing trend in the region from Iberia to the Bay of Biscay to northern Europe; it also appears to have increased slightly in the northern most part of the region (Fig. 5b). Autumn storminess shows a decreasing trend in the region from northern Europe to the North Sea to the Bay of Biscay, and over Central Iberia, with an increasing trend over the Alps and southern Iberia (Fig. 5d). In all four seasons, the trends are field significant at $5 \%$ level, for the field of the 24 triangles (Table 2), according to the Walker's test.

Analyzing extremes of 3-hourly SLP changes derived from in-situ sub-daily pressure observations, Alexander and Tett (2005) and Allan et al. (2009) also reported that the British Isles experienced the most severe storm 

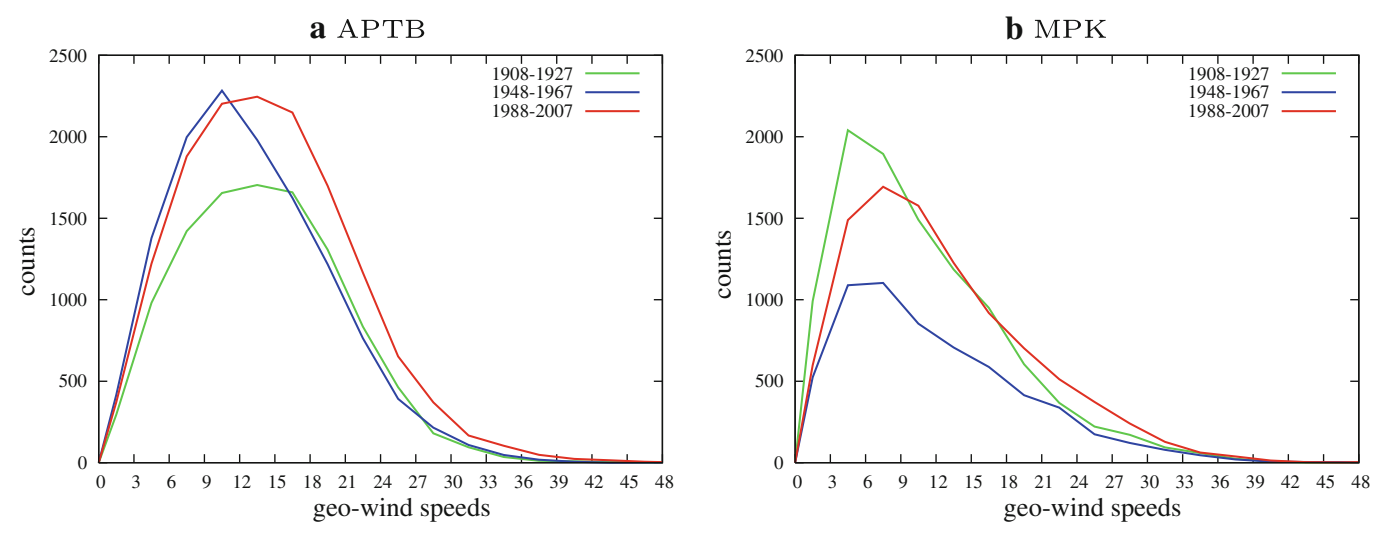

c APTB - 25th percentiles

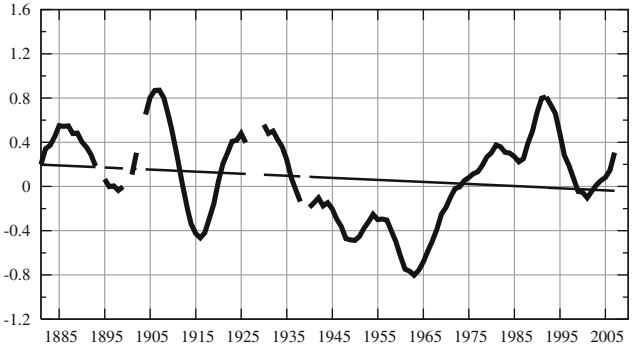

d MPK - 25th percentiles

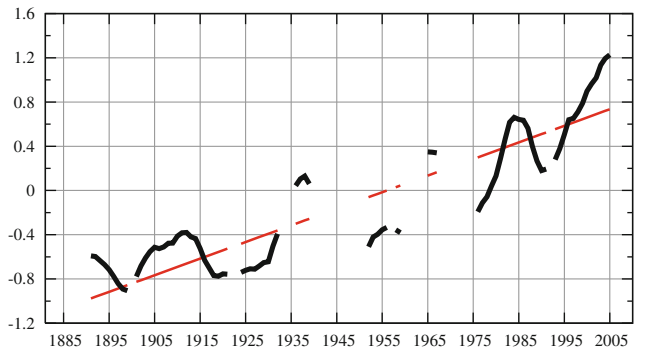

e APTB - 50th percentiles

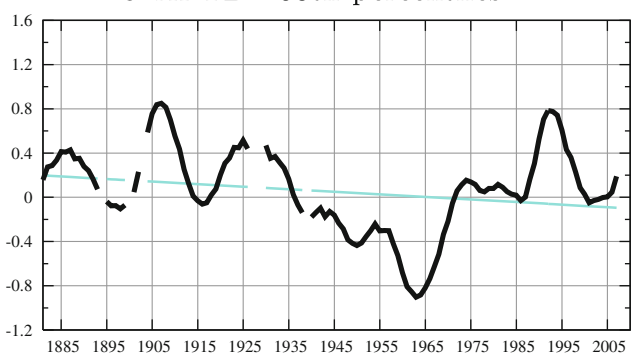

f MPK - 50 th percentiles

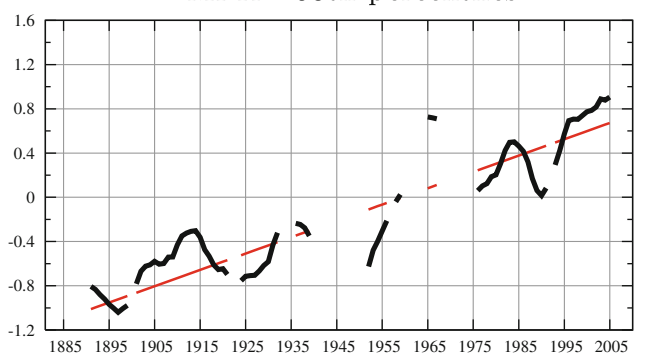

g APTB - 75th percentiles

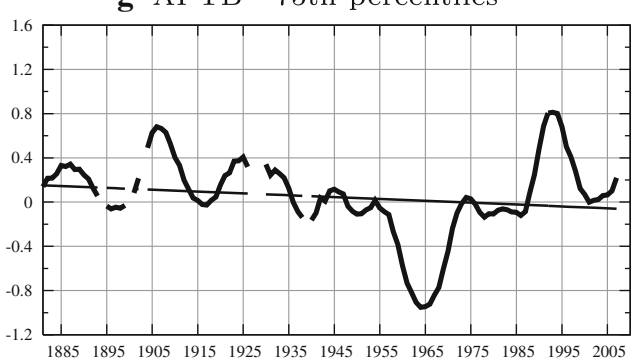

h MPK - 75th percentiles

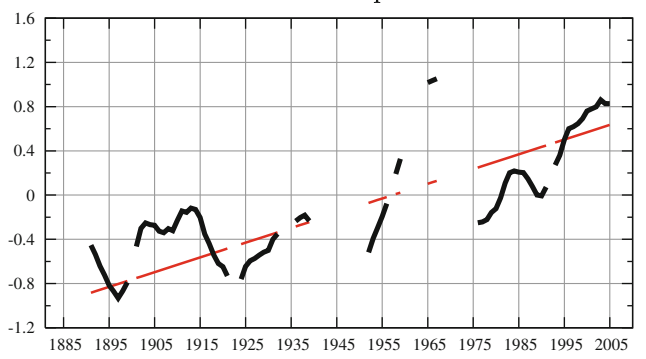

i APTB - 99th percentiles
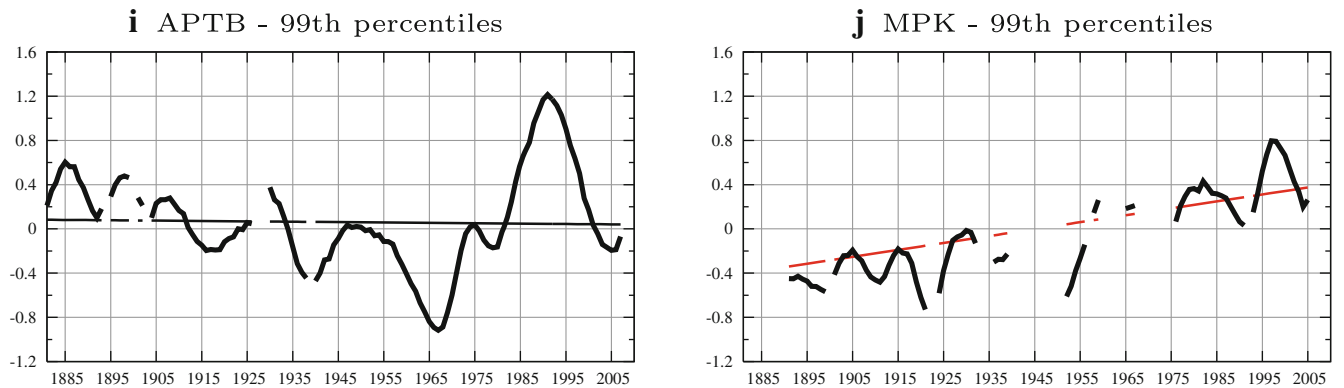

Fig. 6 a, b Sample probability density function of winter (DJF) geostrophic wind speeds $\left(\mathrm{m} \mathrm{s}^{-1}\right)$ over the indicated triangles for the specified 20-year periods. $\mathbf{c}-\mathbf{j}$ Same as in Fig. 3 but for the indicated

seasonal percentiles of standardized winter geostrophic wind speeds over the indicated triangles 
Table 3 Correlations between seasonal NAO indices and the seasonal P95 and P99 storm index series for the period from 1878 or later (see Year1 in this Table) to 2007, with the related significance level $\alpha$ (from a two-sided $t$ test; $(1-\alpha)$ is shown in parentheses). Correlations of at least 5 and 20\% significance are shown in bold and italic, respectively

\begin{tabular}{|c|c|c|c|c|c|c|}
\hline Triangles & Year1 & & DJF & MAM & JJA & SON \\
\hline \multirow[t]{2}{*}{ MGL } & 1890 & 95th & $\mathbf{- 0 . 3 7 4}(1.000)$ & $-0.162(0.897)$ & $-0.077(0.554)$ & $-0.089(0.625)$ \\
\hline & & 99th & $\mathbf{- 0 . 2 8 6}(0.996)$ & $-0.139(0.837)$ & $0.030(0.231)$ & $-0.024(0.189)$ \\
\hline \multirow[t]{2}{*}{ MGB } & 1890 & 95th & $\mathbf{- 0 . 2 1 7}(0.975)$ & $-0.093(0.660)$ & $0.189(0.948)$ & $0.099(0.690)$ \\
\hline & & 99th & $-0.082(0.600)$ & $-0.146(0.867)$ & $0.182(0.940)$ & $0.121(0.784)$ \\
\hline \multirow[t]{2}{*}{ LLM } & 1890 & 95th & $\mathbf{- 0 . 2 9 2}(0.996)$ & 0.278 (0.993) & $\mathbf{0 . 2 2 2}(0.966)$ & $-0.085(0.585)$ \\
\hline & & 99th & $-0.165(0.886)$ & $\mathbf{0 . 3 0 1}(0.997)$ & $0.146(0.831)$ & $-0.145(0.840)$ \\
\hline \multirow[t]{2}{*}{ MPL } & 1890 & 95th & $\mathbf{- 0 . 2 2 7}(0.971)$ & $\mathbf{0 . 3 1 3}(0.998)$ & $0.155(0.863)$ & $-0.077(0.538)$ \\
\hline & & 99th & $-0.082(0.563)$ & $\mathbf{0 . 2 8 1}(0.994)$ & $0.197(0.943)$ & $-0.149(0.847)$ \\
\hline \multirow[t]{2}{*}{ MPB } & 1890 & 95th & $-0.074(0.533)$ & $0.000(0.003)$ & $\mathbf{0 . 2 0 1}(0.955)$ & $0.036(0.277)$ \\
\hline & & 99th & $0.009(0.070)$ & $0.013(0.104)$ & $0.146(0.854)$ & $0.107(0.713)$ \\
\hline \multirow[t]{2}{*}{ PBM } & 1878 & 95th & $\mathbf{- 0 . 2 0 6}(0.958)$ & 0.077 (0.549) & $0.040(0.306)$ & $-0.134(0.813)$ \\
\hline & & 99th & $-0.174(0.914)$ & $0.097(0.658)$ & $-0.101(0.674)$ & $-0.074(0.533)$ \\
\hline \multirow[t]{2}{*}{ MPK } & 1878 & 95th & $-0.167(0.871)$ & $0.022(0.152)$ & $0.032(0.220)$ & $-0.216(0.948)$ \\
\hline & & 99th & $\mathbf{- 0 . 2 5 3}(0.980)$ & $-0.030(0.207)$ & $-0.068(0.453)$ & $-0.087(0.561)$ \\
\hline \multirow[t]{2}{*}{ LVL } & 1894 & 95th & $\mathbf{0 . 3 2 5}(0.999)$ & $0.143(0.841)$ & $\mathbf{0 . 2 2 1}(0.968)$ & $\mathbf{0 . 2 0 6}(0.963)$ \\
\hline & & 99th & $\mathbf{0 . 2 1 4}(0.963)$ & $0.168(0.904)$ & $\mathbf{0 . 2 3 3}(0.977)$ & $-0.017(0.135)$ \\
\hline \multirow[t]{2}{*}{ LVP } & 1894 & 95th & $0.214(0.948)$ & $\mathbf{0 . 3 7 5}(1.000)$ & $0.118(0.727)$ & $0.093(0.626)$ \\
\hline & & 99th & $\mathbf{0 . 2 7 3}(0.987)$ & $\mathbf{0 . 3 8 4}(1.000)$ & $0.169(0.884)$ & $0.198(0.943)$ \\
\hline \multirow[t]{2}{*}{ VDP } & 1892 & 95th & $\mathbf{0 . 2 6 4}(0.984)$ & $\mathbf{0 . 3 4 2}(0.999)$ & $\mathbf{0 . 2 3 9}(0.973)$ & $\mathbf{0 . 2 4 6}(0.977)$ \\
\hline & & 99th & $0.196(0.922)$ & $\mathbf{0 . 2 2 2}(0.959)$ & $\mathbf{0 . 2 5 2}(0.980)$ & $0.151(0.836)$ \\
\hline \multirow[t]{2}{*}{ DKP } & 1892 & 95th & $\mathbf{0 . 3 6 2}(0.999)$ & $0.190(0.916)$ & $0.141(0.794)$ & $\mathbf{0 . 2 2 6}(0.960)$ \\
\hline & & 99th & $\mathbf{0 . 2 8 4}(0.990)$ & $0.163(0.862)$ & $0.097(0.614)$ & $0.148(0.819)$ \\
\hline \multirow[t]{2}{*}{ VKD } & 1892 & 95th & $\mathbf{0 . 2 8 9}(0.995)$ & $\mathbf{0 . 2 1 7}(0.966)$ & $-0.014(0.111)$ & $0.058(0.423)$ \\
\hline & & 99th & $\mathbf{0 . 3 2 4}(0.999)$ & $0.205(0.955)$ & $0.018(0.141)$ & $0.104(0.689)$ \\
\hline \multirow[t]{2}{*}{ KVS } & 1879 & 95th & $\mathbf{0 . 5 4 1}(1.000)$ & $\mathbf{0 . 3 5 2}(1.000)$ & $0.010(0.086)$ & $0.135(0.848)$ \\
\hline & & 99th & $0.509(1.000)$ & $\mathbf{0 . 2 8 6}(0.998)$ & $0.052(0.418)$ & $0.120(0.797)$ \\
\hline \multirow[t]{2}{*}{ VBS } & 1900 & 95th & $\mathbf{0 . 5 5 8}(1.000)$ & $\mathbf{0 . 4 1 3}(1.000)$ & $-0.070(0.500)$ & $0.111(0.714)$ \\
\hline & & 99th & $0.465(1.000)$ & $\mathbf{0 . 3 7 5}(1.000)$ & $-0.084(0.581)$ & $-0.021(0.160)$ \\
\hline \multirow[t]{2}{*}{ APTB } & 1875 & 95th & $\mathbf{0 . 6 7 6}(1.000)$ & $\mathbf{0 . 3 5 5}(1.000)$ & $0.077(0.615)$ & $0.170(0.945)$ \\
\hline & & 99th & $0.568(1.000)$ & $0.292(0.999)$ & $0.030(0.263)$ & $0.095(0.715)$ \\
\hline \multirow[t]{2}{*}{ APVD } & 1904 & 95th & $\mathbf{0 . 6 6 2}(1.000)$ & $\mathbf{0 . 6 0 5}(1.000)$ & $\mathbf{0 . 2 6 1}(0.991)$ & $\mathbf{0 . 4 0 9}(1.000)$ \\
\hline & & 99th & $0.556(1.000)$ & $\mathbf{0 . 5 1 4}(1.000)$ & $\mathbf{0 . 2 1 4}(0.966)$ & $\mathbf{0 . 3 2 6}(0.999)$ \\
\hline \multirow[t]{2}{*}{ BAPV } & 1875 & 95th & $\mathbf{0 . 6 0 0}(1.000)$ & $\mathbf{0 . 2 9 7}(0.999)$ & $0.052(0.444)$ & $0.018(0.162)$ \\
\hline & & 99th & $\mathbf{0 . 5 2 0}(1.000)$ & $\mathbf{0 . 2 5 7}(0.996)$ & $0.134(0.871)$ & $0.066(0.544)$ \\
\hline \multirow[t]{2}{*}{ BBV } & 1901 & 95th & $\mathbf{0 . 5 0 4}(1.000)$ & $\mathbf{0 . 2 9 3}(0.998)$ & $0.045(0.360)$ & $0.156(0.894)$ \\
\hline & & 99th & $0.366(1.000)$ & $0.244(0.989)$ & $\mathbf{0 . 2 0 1}(0.963)$ & $0.165(0.912)$ \\
\hline \multirow[t]{2}{*}{ ВТВ } & 1901 & 95th & $\mathbf{0 . 5 7 3}(1.000)$ & $\mathbf{0 . 3 8 9}(1.000)$ & $-0.189(0.948)$ & $0.109(0.735)$ \\
\hline & & 99th & $0.464(1.000)$ & $0.299(0.998)$ & $-0.103(0.708)$ & $-0.004(0.031)$ \\
\hline \multirow[t]{2}{*}{ DAPV } & 1904 & 95th & $\mathbf{0 . 6 0 6}(1.000)$ & $\mathbf{0 . 4 5 6}(1.000)$ & $0.175(0.916)$ & $\mathbf{0 . 2 5 3}(0.989)$ \\
\hline & & 99th & $\mathbf{0 . 5 3 2}(1.000)$ & $\mathbf{0 . 4 3 2}(1.000)$ & $\mathbf{0 . 2 5 1}(0.987)$ & $0.240(0.983)$ \\
\hline JST & 1923 & 95th & $\mathbf{0 . 3 1 7}(0.990)$ & $0.166(0.818)$ & $\mathbf{0 . 3 0 2}(0.986)$ & $0.225(0.927)$ \\
\hline & & 99th & $\mathbf{0 . 3 1 4}(0.990)$ & $0.127(0.689)$ & $0.181(0.850)$ & $-0.002(0.010)$ \\
\hline JTB & 1923 & 95th & $\mathbf{0 . 4 0 9}(1.000)$ & $0.206(0.940)$ & $0.060(0.412)$ & $0.000(0.003)$ \\
\hline & & 99th & $\mathbf{0 . 3 7 7}(1.000)$ & $0.159(0.852)$ & $0.128(0.751)$ & $0.087(0.566)$ \\
\hline VST & 1900 & 95th & $\mathbf{0 . 5 3 3}(1.000)$ & $\mathbf{0 . 2 8 0}(0.995)$ & $\mathbf{0 . 2 6 6}(0.992)$ & $\mathbf{0 . 3 0 4}(0.998)$ \\
\hline & & 99th & $0.401(1.000)$ & $-0.034(0.264)$ & $0.140(0.834)$ & $0.077(0.550)$ \\
\hline VTAP & 1893 & 95th & $\mathbf{0 . 5 8 8}(1.000)$ & $\mathbf{0 . 3 8 0}(1.000)$ & $0.056(0.449)$ & $\mathbf{0 . 2 9 5}(0.999)$ \\
\hline & & 99th & $\mathbf{0 . 3 7 7}(1.000)$ & $\mathbf{0 . 3 2 2}(0.999)$ & $-0.055(0.442)$ & $0.093(0.675)$ \\
\hline Field signi & level? & 95th & Yes & Yes & No & Yes \\
\hline (Field of 2 & & 99th & Yes & Yes & No & Yes \\
\hline
\end{tabular}


Fig. 7 Simultaneous correlation between seasonal NAO index series (Hurrell 1995) and the seasonal P99 storm index series over each triangle for the period analyzed. The plus and minus signs denote positive and negative correlations respectively. The large, medium, and small signs indicate the correlations are of at least 5, 5 20, and 20 significance, respectively
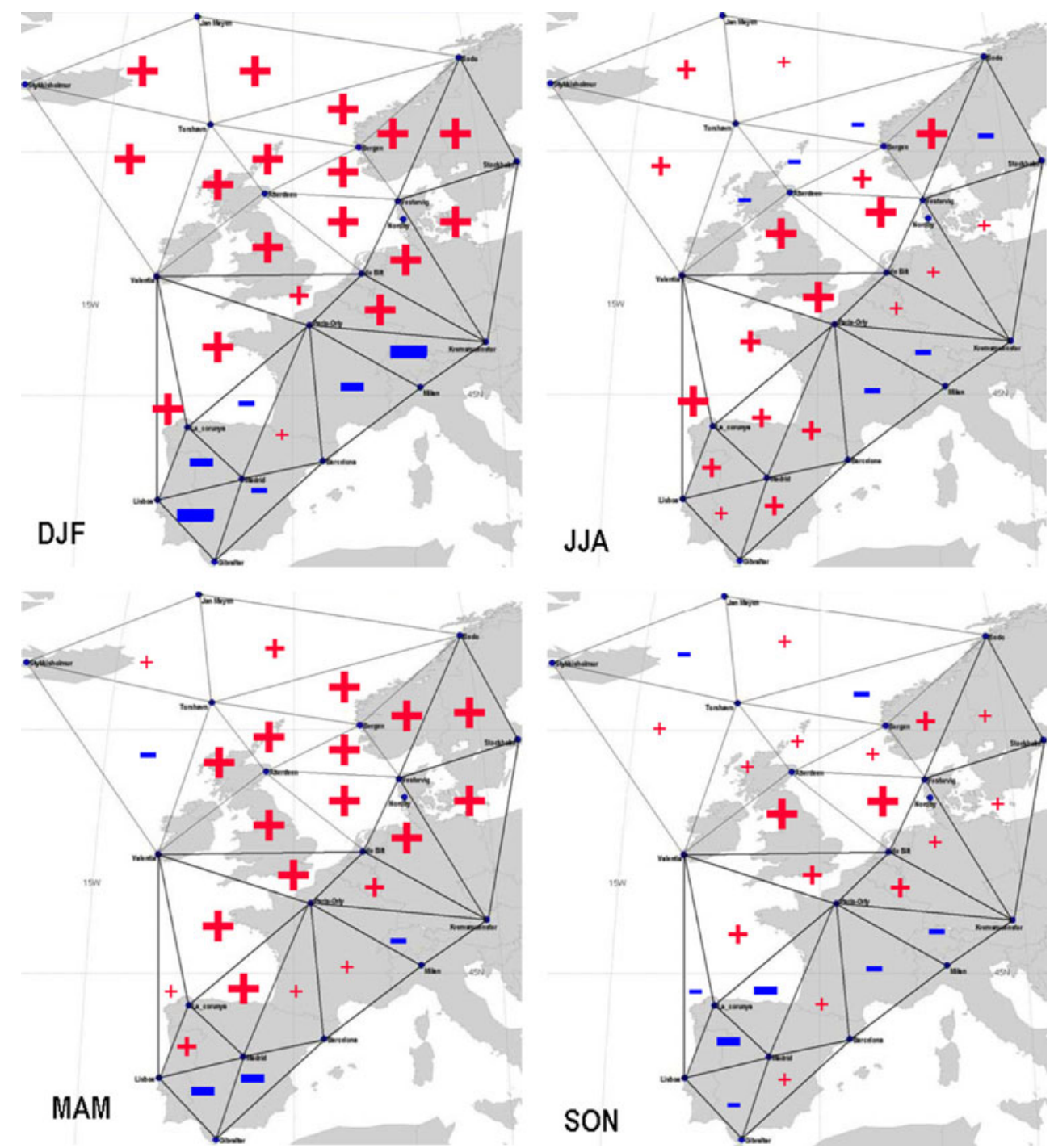

activity in the 1990s over the period from 1920 to 2004. Allan et al. (2009) further reported that in this region severe storms in autumn (OND) and winter (JFM) respond to different physical mechanisms (namely, tropical to mid-latitude North Atlantic and lesser Pacific "ENSO-like" influences dominate in OND, whereas NAO influences predominate in JFM). The seasonal differences in storminess trends and low-frequency variability could be associated with the seasonal variation in the dominating physical mechanisms.

Since individual storms are generally accompanied by precipitation, changes in storminess should be associated with changes in precipitation (Compo and Sardeshmukh 2004). Using data for the period from 1961 to 2000, Fowler and Kilsby (2003a, b) estimated that the recurrence of 10-day precipitation totals with a 50-year return period (based on data for 1961-1990) had increased by a factor of two to five by the 1990s in northern England and Scotland. Trenberth et al. (2007) reported that annual precipitation increased in northern Europe and decreased in the Mediterranean region during the period from 1901 to 2005, and that central and northern Europe exhibited changes primarily in winter, with insignificant changes in summer. These precipitation trends are in general agreement with the above-described historical storminess trends.

\section{Storminess conditions and the NAO}

In this section we briefly discuss the relationship between the NAO and the storminess conditions over the western European region analyzed in this study. There exist several measures of the NAO. The most widely used measure is the difference of normalized sea level pressure (SLP) anomaly between Iceland and the subtropical eastern North Atlantic, such as between Stykkisholmur (Iceland) and Lisbon (Portugal) for the NAO index of Hurrell (1995). Several studies have addressed NAO variability in terms of 
Table 4 Erroneous/suspicious SLP values that were either corrected or set to missing. Other stations are as corrected by Wang et al. (2009)

\begin{tabular}{|c|c|c|c|c|c|c|c|}
\hline $\begin{array}{l}\text { Station } \\
\text { ID }\end{array}$ & Date & $\begin{array}{l}\text { SLP } \\
(\mathrm{hPa})\end{array}$ & Treatment & $\begin{array}{l}\text { Station } \\
\text { ID }\end{array}$ & Date & $\begin{array}{l}\text { SLP } \\
(\mathrm{hPa})\end{array}$ & Treatment \\
\hline 11012 & 1875050613 & 950.9 & 990.9 & 024640 & 1932111218 & 950.3 & $1,050.3$ \\
\hline 11012 & $\begin{array}{llll}1875 & 05 & 10 & 13\end{array}$ & 949.6 & 994.6 & 024640 & 1932111306 & 950.9 & $1,050.9$ \\
\hline 11012 & 1908042713 & 941.1 & 971.1 & 024640 & 1938121706 & 952.6 & $1,052.6$ \\
\hline 11012 & 1974051813 & 938.5 & 978.5 & 024640 & $\begin{array}{llll}1938 & 12 & 17 & 12\end{array}$ & 953.3 & $1,053.3$ \\
\hline 11012 & 1974091113 & 941.2 & 981.2 & 024640 & 1938121718 & 953.2 & $1,053.2$ \\
\hline 11012 & 1976051713 & 948.9 & 978.9 & 024640 & 1938121806 & 950.0 & $1,050.0$ \\
\hline \multirow[t]{2}{*}{110120} & 1992071015 & $1,085.0$ & $1,008.5$ & & & & \\
\hline & & & & 160800 & 1981072621 & $1,000.9$ & $1,020.9$ \\
\hline 01387 & 1979012721 & 503.1 & Set to missing & 160800 & 1981072700 & $1,000.9$ & $1,020.9$ \\
\hline 01387 & 1980022900 & $1,059.9$ & $1,029.9$ & 160800 & 1984111312 & 700.1 & Set to missing \\
\hline 01387 & 1980022903 & $1,059.9$ & $1,029.9$ & 160800 & 1996062212 & 988.3 & 998.3 \\
\hline 01387 & 1990100715 & 989.6 & Set to missing & 160800 & 1996062223 & 995.3 & $1,005.3$ \\
\hline 01387 & 1991082409 & 989.8 & Set to missing & 160800 & 1996062401 & $1,006.1$ & $1,016.1$ \\
\hline 01387 & 2004051206 & 921.9 & $1,021.9$ & 160800 & 1998061221 & 997.3 & $1,007.3$ \\
\hline 01387 & 2004061806 & 981.9 & Set to missing & 160800 & 1998061222 & 998.4 & $1,008.4$ \\
\hline \multirow[t]{2}{*}{01387} & 2006032006 & $1,052.7$ & Set to missing & & & & \\
\hline & & & & 0201E & 1860040508 & $1,033.7$ & Set to missing \\
\hline 03195 & 1893030310 & 975.5 & Set to missing & 0201E & 1860040515 & 982.0 & Set to missing \\
\hline 03195 & 1977020609 & $1,003.2$ & $1,033.2$ & 0201E & 1888012008 & $1,006.8$ & Set to missing \\
\hline 03195 & 1977020612 & $1,003.2$ & $1,033.2$ & 0201E & 1895021515 & $1,056.8$ & $1,006.8$ \\
\hline \multirow[t]{2}{*}{03195} & 2003103021 & $1,011.0$ & $1,001.0$ & 0201E & 1910030217 & 981.5 & Set to missing \\
\hline & & & & 0201E & 1913010217 & $1,000.8$ & $1,020.8$ \\
\hline 08495 & 1935111107 & $1,040.0$ & Set to missing & 0201E & 1913101217 & $1,047.9$ & $1,024.8$ \\
\hline 08495 & 1935111110 & $1,043.8$ & Set to missing & 0201E & 1914121009 & 982.4 & Set to missing \\
\hline 08495 & 1935111113 & $1,043.8$ & Set to missing & 0201E & 1918012517 & $1,006.6$ & Set to missing \\
\hline 08495 & 1935111116 & $1,044.1$ & Set to missing & 0201E & 1919062417 & 992.8 & Set to missing \\
\hline \multirow[t]{2}{*}{08495} & $193511 \quad 1213$ & $1,052.0$ & $1,022.0$ & 0201E & 1923012117 & 945.2 & Set to missing \\
\hline & & & & 0201E & 1928081617 & $1,105.7$ & $1,015.7$ \\
\hline 085360 & 1937051812 & $1,038.5$ & $1,018.5$ & 0201E & 1931020717 & 101.2 & $1,011.2$ \\
\hline 085300 & 1991030600 & $1,087.6$ & 987.6 & 0201E & 1931100717 & 108.7 & $1,018.7$ \\
\hline 085300 & 1991030606 & $1,082.3$ & 982.3 & 0201E & 1933092917 & 106.2 & $1,016.2$ \\
\hline 085300 & 1991030609 & $1,088.3$ & 988.3 & 0201E & 1934042017 & 109.3 & $1,019.3$ \\
\hline 085300 & 1991030612 & $1,086.3$ & 986.3 & 081810 & $197303 \quad 1215$ & 952.1 & Set to missing \\
\hline 085300 & 1991030618 & $1,083.7$ & 983.7 & 081810 & $197303 \quad 1218$ & 914.2 & $1,014.2$ \\
\hline 085300 & 1991030700 & $1,081.4$ & 981.4 & 081810 & $197303 \quad 1221$ & 914.7 & $1,014.7$ \\
\hline 085300 & 1991030706 & $1,077.5$ & 977.5 & 081810 & 1983062106 & 997.7 & $1,017.7$ \\
\hline 085300 & 1991030709 & $1,078.6$ & 978.6 & 081810 & 1986013100 & $1,078.7$ & 978.7 \\
\hline 085300 & 1991030712 & $1,081.5$ & 981.5 & 081810 & 1989022600 & $1,082.8$ & 982.8 \\
\hline 085300 & 1991030718 & $1,086.5$ & 986.5 & 081810 & 1989022603 & $1,085.0$ & 985.0 \\
\hline 085300 & 1991030800 & $1,087.4$ & 987.4 & 081810 & 1997110609 & $1,089.9$ & 989.9 \\
\hline 085300 & 2000122118 & $1,087.5$ & 987.5 & 081810 & 1997110612 & $1,089.7$ & 989.7 \\
\hline 085300 & 2007071106 & $1,002.0$ & $1,020.0$ & 081810 & 1997110615 & $1,089.5$ & 989.5 \\
\hline
\end{tabular}

empirical orthogonal functions (EOFs) or rotated EOFs (e.g., Wallace and Gutzler 1981; Folland et al. 2009). A seasonally and geographically varying "mobile" index of the NAO (NAOm) has also been defined as the difference between normalized SLP anomalies at the locations of maximum negative correlation between the subtropical and 
subpolar North Atlantic SLP (Portis et al. 2001). In terms of the NAOm, the subtropical nodal point of the NAO migrates westward and slightly northward into the central North Atlantic from winter to summer, and the NAO's nodes maintain their correlation from winter to summer to a greater degree than traditional NAO indices based on fixed stations in the eastern North Atlantic (Portis et al. 2001). Folland et al. (2009) also report that the summer NAO is characterized by a more northerly location and smaller spatial scale than its winter counterpart. In this study, we use the NAO index of Hurrell (1995), as updated by W09, because the pressure records from both Stykkisholmur and Lisbon are included in the geostrophic winds (a better match in location). There is also a large antecedent literature that uses the Hurrell index.

European surface air temperature and precipitation are strongly affected by the NAO (Hurrell and van Loon 1997; Hurrell 1995; Alexandersson et al. 1998). It is also associated with the tendency for inverse variations in precipitation between northern Europe and the Mediterranean (Dickson et al. 2000; Hurrell and van Loon 1997; Trenberth et al. 2007). For instance, a more positive NAO in the 1990s was associated with wetter conditions in northern Europe and drier conditions over the Mediterranean and northern African regions (Dickson et al. 2000; Trenberth et al. 2007). Significant relationships between the NAO and storminess conditions in the North Atlantic domain have also been reported in several studies (e.g., Wang et al. 2009; Chang 2009; Wang et al. 2006b; Allan et al. 2009; Jung et al. 2003; Ulbrich and Christoph 1999).

Simultaneous correlations between seasonal NAO index series and the P95 and P99 storm indices were calculated for the period from 1878 or later to 2007 and reported in Table 3, along with the corresponding significance level and field significance. For the P99 storm index, the significance level is also shown in Fig. 7. In winter, highly significant positive correlations are seen over northern and central parts of the region analyzed, with negative correlations for the southern part (Iberia and Alps; Fig. 7, DJF). A similar pattern, but with slightly weaker correlations, is also seen in spring (Fig. 7, MAM). However, the correlations are much weaker in summer and autumn (Fig. 7, JJA and SON). Over Iberia, the correlations in summer are very different from those in the other seasons, featuring marginally significant positive correlations in summer but mostly negative correlations in the other seasons (Fig. 7; Table 3). For the field of the 24 triangles, the correlations are field significant at 5\% level in winter, spring, and autumn, but insignificant in summer (Table 3, last rows), according to the Walker's test.

We speculate that the seasonality of the NAO-storminess relationship arises from the seasonal migration of the storm track and the seasonal variations in the two poles of the NAO, the Azores High and the Icelandic Low. In winter, the Azores High center locates around $30^{\circ} \mathrm{N}$ latitude (south of the Azores). The Iberian peninsula lies in the northern periphery of the high pressure ridge, and northcentral Europe lies in the region of largest pressure gradient between the two poles of the NAO. Thus, a stronger positive NAO is associated with stormier winters in northcentral Europe but less stormy winters in the Iberian peninsula (a stronger Azores High could even control the Iberian peninsula), as shown in Fig. 7 (DJF). In summer, while the Icelandic Low weakens, the Azores High center moves northward to around $35^{\circ} \mathrm{N}$, often building a ridge across France and the Alps region, bringing hot and dry weather to these areas. In this situation, the Iberian peninsula lies in the southern periphery of the Azores High, where African easterly waves are impelled, favouring tropical cyclonegenesis. Therefore, a stronger positive NAO is associated with stormier summers in the Iberian peninsula (Fig. 7, JJA).

Further, we calculate the series of normalized monthly mean pressure differences between Paris and Torshavn. Except that a different pair of stations is used, this series is similar to the monthly NAO index series, representing pressure gradients between the two stations in question. In order to estimate the percentage of the NAO interannual variance that can be accounted for by this pressure gradient index, we regress the seasonal mean NAO index series on the corresponding seasonal mean series of the pressure differences in each of the four seasons of year, separately. The results show that the Par-Tor pressure gradients account for $0.1,33.5,27.0$, and $30.3 \%$ of the NAO interannual variance in DJF, MAM, JJA, and SON, respectively. The very small percentage in winter (DJF) is speculated to be due to the fact that both Paris and Torshavn are within the same center of action of the NAO in winter.

\section{Conclusions}

We have analyzed extremes of geostrophic wind speeds derived from sub-daily SLP observations at 13 sites in the western European region from the Iberian peninsula to Scandinavia for the period from 1878 or later to 2007 , as an extension of the previous studies on storminess conditions in the Northeast (NE) Atlantic-European region. We have also updated the results for the 10 triangles analyzed in W09 using a re-sampling technique to reduce aliasing effects, which are found to be very small and do not change the conclusions. We have also briefly discussed the relationship between the storminess conditions and the North Atlantic Oscillation (NAO).

The results show that storminess conditions in this European region have undergone substantial decadal or 
longer time scale fluctuations, with considerable seasonal and regional differences (especially between winter and summer, and between the British Isles-North Sea area and other parts of the region). The previously reported trends seen in the second half of the twentieth century (McCabe et al. 2001; Gulev et al. 2001; Wang et al. 2006a, b) seem to have continued into the early twenty-first century. The winter storminess trends are characterized by increases in the Alps region, with slight decreases in northern Europe and in the region from northwestern Iberia northeastward to the southern UK. In particular, there has been a notable increase in the upper tail of the distribution of geostrophic wind speeds in the recent decades in both the North Sea and the Alps areas; the occurrence frequency of strong geostrophic winds has increased notably from the mid to the late twentieth century. Decreases are also seen in spring storminess over the region from northwestern Iberia to the Bay of Biscay to northern Europe. In summer and autumn, storminess trends are characterized by decreases in the region from the Bay of Biscay to the North Sea to central Europe, with increases in the French Alps and southern Iberia. The results also show that, in the cold season (December-March), the NAO-storminess relationship is significantly positive in the north-central part of this region, but negative in the south-southeastern part. The NAOstorminess relationship revealed in this study is consistent with the results of previous studies (e.g. Chang 2009; Folland et al. 2009; Gulev et al. 2001; Serreze et al. 1997).

Acknowledgments The authors are very grateful to all members of GCOS/WCRP AOPC/OOPC (Atmosphere/Ocean Observation Panel for Climate) Working Group on Surface Pressure for providing us with access to the International Surface Pressure Databank, which includes almost all the pressure data we analyzed in this study. Dr. José Antonio López of the Spanish State Meteorological Agency is also acknowledged for providing extra data to fill in data gaps in the records of two Spanish stations in the ISPD. Rob Allan is primarily funded as Program Manager of the international Atmospheric Circulation Reconstructions over the Earth (ACRE) initiative by the Queensland Climate Change Centre of Excellence (QCCCE) in Australia, with some additional funds from the UK Joint Department of Energy and Climate Change (DECC) and Department for Environment, Food and Rural Affairs (Defra) Integrated Climate Programme, DECC/Defra (GA01101). The authors also wish to thank Drs. Xuebin Zhang and Seung-Ki Min for their useful internal review of an earlier version of this manuscript, and the two anonymous reviewers for their helpful review comments.

\section{Appendix: Data quality control and interpolation procedures}

As in W09, a site in this study also refers to the combination of two or more stations that are very close to each other; and each SLP data series is also first screened for large random errors and then interpolated in time, using a natural spline fit, to ensure that the three sites that form a triangle have SLP values for the same hours (see W09 for more details). The screening for large random errors is done by checking if the pressure tendency lies within pre-set limits and comparing the segment of SLP observation with the corresponding segment of observations at the available nearest stations (see Appendix A in W09 for details). Table 4 lists the erroneous/ suspicious SLP values identified for the 9 sites that were not previously analyzed (sites 1-9 in Table 1). Note that the general characteristics of the decadal or longer time scale storminess variability are not significantly affected by the correction or exclusion of these erroneous/suspicious SLP values, which, however, does make a few outliers disappear.

\section{Reference}

Alexander LV, Tett SFB (2005) Recent observed changes in severe storms over the United Kingdom and Iceland. Geophys Res Lett 32:L13704. doi:10.1029/2005GL022371

Alexandersson H, Tuomenvirta H, Schmith T, Iden K (2000) Trends of storms in NW Europe derived from an updated pressure data set. Clim Res 14:71-73

Alexandersson H, Schmith T, Iden K, Tuomenvirta H (1998) Longterm variations of the storm climate over NW Europe. Glob Atmos Ocean Syst 6:97-120

Allan R, Tett S, Alexander LV (2009) Fluctuations of autumn-winter severe storms over the British Isles: 1920 to present. Int J Climatol 29:357-371. doi:10.1002/joc.1765

Chang EKM (2009) Are band-pass variance statistics useful measures of storm track activity? Re-examining storm track variability associated with the NAO using multiple storm track measures. Clim Dyn 33:277-296. doi:10.1007/s00382-009-0532-9

Compo GP, Sardeshmukh PD (2004) Storm track predictability on seasonal and decadal scales. J Clim 17:3701-3720

Compo GP et al (2011) The twentieth century reanalysis project. Q J R Meteorol Soc 137:1-28

Della-Marta PM, Pinto JG (2009) Statistical uncertainty of changes in winter storms over the North Atlantic and Europe in an ensemble of transient climate simulations. Geophys Res Lett 36:L14703. doi:10.1029/2009GL038557

Dickson RR et al (2000) The Arctic Ocean response to the North Atlantic oscillation. J Clim 13:2671-2696

Folland CK, Knight J, Linderholm HW, Fereday D, Ineson S, Hurrell JW (2009) The summer North Atlantic oscillation: past, present, and future. J Clim 22:1082-1103. doi:10.1175/2008JCLI2459.1

Fowler HJ, Kilsby CG (2003) Implications of changes in seasonal and annual extreme rainfall. Geophys Res Lett 30:1720. doi: $10.1029 / 2003017327$

Fowler HJ, Kilsby CG (2003) A regional frequency analysis of United Kingdom extreme rainfall from 1961 to 2000. Int J Climatol 23:1313-1334

Gulev SK, Grigorieva V (2006) Variability of the winter wind waves and swell in the North Atlantic and North Pacific as revealed by the voluntary observing ship data. J Clim 19:5667-5785

Gulev SK, Grigorieva V (2004) Last century changes in ocean wind wave height from global visual wave data. Geophys Res Lett 31:L24302. doi:10.1029/2004GL021040

Gulev SK, Zolina O, Grigoriev S (2001) Extratropical cyclone variability in the Northern Hemisphere winter from the NNRs/ NCAR reanalysis data. Clim Dyn 17:795-809 
Hurrell JW (1995) Decadal trends in the North Atlantic oscillation: regional temperatures and precipitation. Science 269:676-679

Hurrell JW, van Loon H (1997) Decadal variations associated with the North Atlantic oscillation. Clim Change 36:301-326

Ihara C, Kushner Y (2009) Change of mean mid-latitude westerlies in the 21 st century climate simulations. Geophys Res Lett 36:L13701. doi:10.1029/2009GL037674

IPCC (2007) Summary for policymakers. In: Solomon S et al (eds) Climate change 2007: the physical science basis. Contribution of working group I to the fourth assessment report of the intergovernmental panel on climate change. Cambridge University Press, Cambridge, UK and New York, USA, 944 pp

Jung T, Hilmer M, Ruprecht E, Kleppek S, Gulev SK, Zolina O (2003) Characteristics of the recent eastward shift of interannual NAO variability. J Clim 16:3371-3382

Kushner PJ, Held IM, Delworth TL (2001) Southern Hemisphere atmospheric circulation response to global warming. J Clim 14:2238-2249

Lambert S, Fyfe JC (2006) Changes in winter cyclone frequencies and strengths simulated in enhanced greenhouse gas experiments: results from the models participating in the IPCC diagnostic exercise. Clim Dyn 26:713-728. doi:10.1007/s00382-006-0110-3

Leckebusch GC, Koffi B, Ulbrich U, Pinto JG, Spangehl T, Zacharias S (2006) Analysis of frequency and intensity of winter storm events in Europe on synoptic and regional scales from a multimodel perspective. Clim Res 31:59-74

Livezey RE, Chen WY (1983) Statistical field significance and its determination by Monte Carlo techniques. Mon Weather Rev 111:46-59

Loeptien U, Zolina O, Gulev S, Latif M, Soloviov V (2008) Cyclone life cycle characteristics over the Northern Hemisphere in coupled GCMs. Clim Dyn 31:507-532. doi:10.1007/s00382-007-0355-5

Lorenz DJ, DeWeaver ET (2007) Tropopause height and zonal wind response to global warming in the IPCC scenario integrations. J Geophys Res 112:D10119. doi:10.1029/2006JD008087

Madden RA, Jones RH (2001) A quantitative estimate of the effect of aliasing in climatological time series. J Clim 14:3987-3993

Matulla C, Schoener W, Alexandersson H, von Stroch H, Wang XL (2008) European storminess: late nineteenth century to present. Clim Dyn 31:125-130. doi:10.1007/s00382-007-0333-y

McCabe GJ, Clark MP, Serreze MC (2001) Trends in Northern Hemisphere surface cyclone frequency and intensity. J Clim 14:2763-2768

Meehl GA et al (2007) Global climate projections. In: Solomon S et al (eds) Climate change 2007: the physical science basis. Contribution of working group I to the fourth assessment report of the intergovernmental panel on climate change. Cambridge University Press, Cambridge, UK and New York, USA, 944 pp

Portis DH, Walsh JE, Hamly ME, Lamb PJ (2001) Seasonality of the North Atlantic oscillation. J Clim 14:2069-2078

Schinke H (1993) On the occurrence of deep cyclones over Europe and the North Atlantic in the period 1930-1991. Contrib Atmos Phys 66(3):223-237

Schmidt H, von Storch H (1993) German Bight storms analyzed. Nature 365:791
Serreze MC, Carse F, Barry RG, Rogers JC (1997) Icelandic low cyclone activity: climatological features, linkages with the NAO, and relationships with recent changes in the Northern Hemisphere circulation. J Clim 10(3):453-464

Solomon S et al (2007) Technical summary. In: Solomon S et al (eds) Climate change 2007: the physical science basis. Contribution of working group I to the fourth assessment report of the intergovernmental panel on climate change. Cambridge University Press, Cambridge, UK and New York, USA, 944 pp

Sweeney J (2000) A three-century storm climatology for Dublin 1715-2000. Irish Geogr 33(1):1-14

Trenberth KE et al (2007) Observations: surface and atmospheric climate change. In: Solomon S et al (eds) Climate change 2007: the physical science basis. Contribution of working group I to the fourth assessment report of the intergovernmental panel on climate change. Cambridge University Press, Cambridge, UK and New York, USA, $944 \mathrm{pp}$

Ulbrich U, Leckebusch GC, Pinto JG (2009) Extra-tropical cyclones in the present and future climate: a review. Theor Appl Climatol 96:117-131. doi:10.1007/s00704-008-0083-8

Ulbrich U, Christoph M (1999) A shift of the NAO and increasing storm track activity over Europe due to anthropogenic greenhouse gas forcing. Clim Dyn 15:551-559

von Storch H et al (1993) Changing statistics of storms in the North Atlantic. MPI report 116, Hamburg, 23 pp

Wallace JM, Gutzler DS (1981) Teleconnections in the peopotential height field during the Northern Hemisphere winter. Mon Weather Rev 109:784-812

Wang XLL, Zwiers FW, Swail VR, Feng Y (2009) Trends and variability of storminess in the Northeast Atlantic region, 1874-2007. Clim Dyn 33:1179-1195. doi:10.1007/s00382-0080504-5

Wang XL, Swail VR, Zwiers FW, Zhang X, Feng Y (2008) Detection of external influence on trends of atmospheric storminess and ocean wave heights. Clim Dyn 32:189-203. doi:10.1007/ s00382-008-0442-2

Wang XLL, Swail VR (2006) Historical and possible future changes of wave heights in northern hemisphere oceans. Atmos Ocean Interact 2. In: Perrie W (ed) Advances in fluid mechanics series, vol 39. Wessex Institute of Technology Press, Southampton, $240 \mathrm{pp}$

Wang XLL, Swail VR, Zwiers FW (2006) Climatology and changes of extra-tropical cyclone activity: comparison of ERA-40 with NCEP/NCAR reanalysis for 1958-2001. J Clim 19:3145-3166. doi:10.1175/JCLI3781.1

Wang XLL, Wan H, Swail VR (2006) Observed changes in cyclone activity in Canada and their relationships to major circulation regimes. J Clim 19(6):896-915. doi:10.1175/JCLI3664.1

Wilks DS (2006) On "Field Significance" and the false discovery rate. J Appl Meteorol Climatol 45:1181-1189. doi:10.1175/JAM2404.1

Yin X, Gleason, BE, Vose RS, Compo GP, Matsui N (2008) The International Surface Pressure Databank (ISPD) Version 2.2. National Climatic Data Center, Asheville, pp 1-12. Accessible at ftp://ftp.ncdc.noaa.gov/pub/data/ispd/doc/ISPD2_2.pdf 